\title{
Linear and nonlinear optical properties of silver nanoparticles synthesized in dielectrics by ion implantation and laser annealing
}

\author{
Andrey L. Stepanov \\ Kazan Physical-Technical Institute, Russian Academy of Sciences \\ Russian Federation \\ Laser Zentrum Hannover \\ Germany
}

\section{Introduction}

Composite metamaterials containing metallic nanoparticles (MNPs) are now as considered a basis for designing new photonic media for optoelectronics and nonlinear optics (Sarychev \& Shalaev, 2007). Simultaneously with the search for and development of modern technologies intended for nanoparticle synthesis, substantial practical attention has been devoted to designing techniques for controlling the MNP size. This is caused by the fact that the properties of MNPs, such as the quantum size effect, single-electron conduction, etc., which are required for various applications, take place up to a certain MNP size. An example of their application in optoelectronics is a prototype of integrated electronic circuit - chip that combines metallic wires as conductors of electric signals with fibers as guides of optical signals. In practice, light guides are frequently made of synthetic sapphire or silicon oxide, which are deposited on or buried in semiconductor substrates. In this case, electrooptic emitters and that accomplish electric-to-optic signal conversion are fabricated inside the dielectric layer. This light signal from a microlaser is focused in a light guide and then transmitted through the optoelectronic chip to a high-speed photodetector, which converts the photon flux to the flux of electrons. It is expected that light guides used instead of metallic conductors will improve the data rate by at least two orders of magnitude. Moreover, there is good reason to believe that optical guide elements will reduce the energy consumption and heat dissipation, since metallic or semiconductor components of the circuits may be replaced by dielectric ones in this case. Prototype optoelectronic chips currently available are capable of handling data streams with a rate of $1 \mathrm{Gbit} / \mathrm{s}$, with improvement until $10 \mathrm{Gbit} / \mathrm{s}$ in future.

Key elements of dielectric waveguides used for light propagation are nonlinear optical switches, which must provide conversion of laser signal for pulse duration as short as picoor femtoseconds. The nonlinear optical properties of MNP-containing dielectrics stem from the dependence of their refractive index and nonlinear absorption on incident light intensity 
(Flytzanis et al., 1991). This effect is associated with MNPs, which exhibit an enhancement of local electromagnetic field in a composite and, as consequence, a high value of the third order nonlinear susceptibility when exposed to ultrashort laser pulses. Therefore, such MNP-containing dielectric materials may be used to advantage in integrated optoelectronic devices, for example, as shown in Fig. 1.

It is well known (Kreibig \& Vollmer, 1995) that a local field enhancement in MNPs stimulates a strong linear optical absorption called as surface plasmon resonance (SPR). The electron transitions responsible for plasmon absorption in MNPs cause also a generation of an optical nonlinearity of a composite in the same spectral range. As a result, the manifestation of nonlinear optical properties is most efficient for wavelengths near the position of a SPR maximum. In practice, to reach the strong linear absorption of a composite in the SPR spectral region, attempts are made to increase the concentration (filling factor) of MNPs. Systems with a higher filling factor offer a higher nonlinear susceptibility, when all other parameters of composites being the same. Usually noble metals and copper are used to fabricate nonlinear optical materials with high values of third order susceptibility. There are variety ways to synthesis MNPs in dielectrics, such as magnetron sputtering, the convective method, ion exchange, sol-gel deposition, etc. One of the most promising enhanced fabrication methods is ion implantation (Townsend et al., 1994, Stepanov, 2005a) because it allows reaching a high metal filling factor in an irradiated matrix beyond the equilibrium limit of metal solubility and provides controllable synthesis of MNPs at various

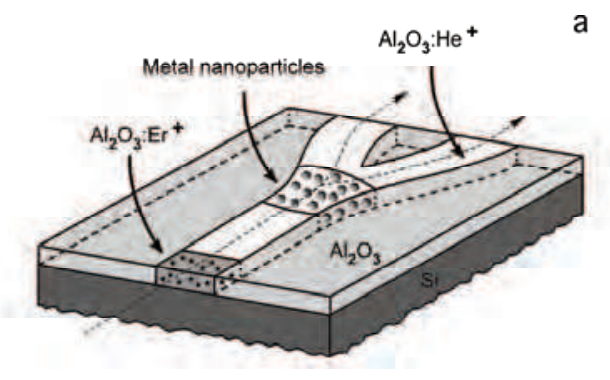

b

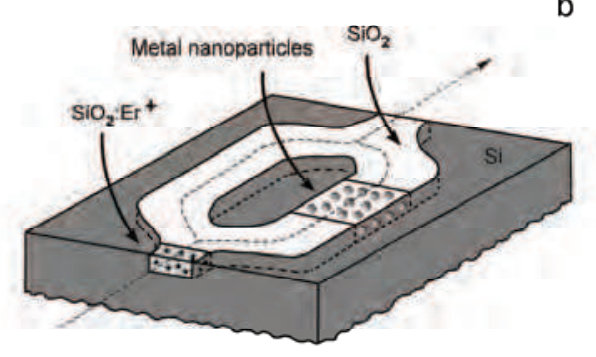

Fig. 1. Prototypes of optoelectronic chip with a dielectric waveguide combined with silicone substrate. Ion implantation can be applied to fabricate selective area doped by rear metal ions (marked by stars) to work as microlaser and to illuminate in waveguide, created by rear-gas ion radiation with MNPs to form an optical switcher. 
depths under the substrate surface. Nearly any metal-dielectric composition may be produced using ion implantation. This method allows for strict control of the doping ion beam position on the sample surface with implant dose as, for example, in the case of electron- and ion-beam lithography. Ion implantation is widely used in industrial semiconductor chip fabrication. Therefore, the combination of MNP-containing dielectrics with semiconductor substrates by same technological approach as ion implantation could be reached quite effective. Moreover, ion implantation can be applied for different steps in optoelectronic material fabrication such as creation of optical waveguides by implantation with rear gas ions $\left(\mathrm{H}^{+}, \mathrm{He}^{+}\right.$etc.), a designing of electric-to-optic signal convectors and microlaser by irradiation of dialectics waveguides with rear metal ions $\left(\mathrm{Er}^{+}, \mathrm{Eu}^{+}\right.$etc.) and a synthesis of MNPs (Fig. 1).

The history of MNP synthesis in dielectrics by ion implantation dates back to 1973, when a team of researchers at the Lyons University in France (Davenas et al., 1973, Treilleux et al., 1978) pioneered this method to create particles of various metals (sodium, calcium, etc.) in $\mathrm{LiF}$ and $\mathrm{MgO}$ ionic crystals. First work on ion-synthesis of noble nanoparticles was done in study of Au- and Ag-irradiated lithia-alumina-silica glasses (Arnold et al., 1975, Arnold \& Borders, 1977). Later developments have expanded from the metal implants to the use of many ions and the active formation of compounds, including metal alloys and totally different composition precipitate inclusions. In ion implantation practice MNPs were fabricated in various materials, such as polymers, glass, artificial crystals, and minerals. By implantation, one can produce almost any metal-dielectric composite metamaterials, as follows from Table 1, which gives a comprehensive list of references of various dielectrics with implanted silver nanoparticles with conditions for their fabrications. This chapter focuses on recent advantages in fabrication of silver nanoparticles by low-energy in implantation in various inorganic matrixes. Also some examples of nonlinear optical repose in such composites are presented and discussed.

\section{Ion synthesis of metal nanoparticles}

Ion implantation is an effective technological tool for introducing single impurities into the surface layer of the substrate to a depth of several micrometers. The degree of surface modification of the materials depends on their individual chemical and structural properties, as well as on variations of implantation parameters, such as the type and energy of an implant, current density in ion beam, substrate temperature, etc. A most critical parameter is ion dose $F_{0}$, which determines the implant amount. Depending on the modification of dielectrics by irradiation, ion implantation can be conventionally divided into low-dose and high-dose processes.

In the case of low-dose irradiation $\left(\sim F_{0} \leq 5.0 \cdot 10^{14} \mathrm{ion} / \mathrm{cm}^{2}\right)$, the Ag ions implanted, after stopping and thermalization, are dispersed throughout the volume of the dielectrics and are well separated from each other. The energy of the implant is transferred to the matrix via electron shell excitation (ionization) and nuclear collisions. This causes radiation-induced defects, which, in turn, may reversibly or irreversibly modify the material structure (Townsend et al., 1994). Various types of crystal structure damage have been observed in practice : extended and point defects, amorphization and local crystallization, precipitation of a new phase made up of host atoms or implanted ions, etc. 


\begin{tabular}{|c|c|c|c|c|c|}
\hline $\begin{array}{c}\text { Matrix } \\
\text { type }\end{array}$ & $\begin{array}{c}\text { Ion } \\
\text { energy, } \\
\text { keV }\end{array}$ & $\begin{array}{l}\text { Ion dose, } \\
\text { ion } / \mathrm{cm}^{2}\end{array}$ & $\begin{array}{c}\text { Current } \\
\text { density, } \\
\mu \mathrm{A} / \mathrm{cm}^{2}\end{array}$ & $\begin{array}{c}\text { Post- } \\
\text { implantation } \\
\text { heat treatment }\end{array}$ & Authors \\
\hline $\begin{array}{l}\mathrm{Al}_{2} \mathrm{O}_{3} \\
\text { crystal } \\
<1010>\end{array}$ & $\begin{array}{c}50 \\
360\end{array}$ & $\begin{array}{l}4.0 \cdot 10^{16} \\
5.0 \cdot 10^{16} \\
8.0 \cdot 10^{16}\end{array}$ & $1-5$ & $\begin{array}{l}\text { Annealing in } \\
\text { air at } 650^{\circ} \mathrm{C} \text {, } \\
30 \text { min }\end{array}$ & $\begin{array}{l}\text { Rahmani et al., } \\
\text { 1988, Rahmani \& } \\
\text { Townsend 1989 }\end{array}$ \\
\hline $\begin{array}{l}\mathrm{Al}_{2} \mathrm{O}_{3} \\
\text { crystal } \\
<0001>\end{array}$ & $\begin{array}{l}1.5 \cdot 10^{3} \\
1.8 \cdot 10^{3}\end{array}$ & $(0.2-2.0) \cdot 10^{17}$ & & $\begin{array}{l}\text { Annealing in } \\
\text { air at } 1100^{\circ} \mathrm{C} \text {, } \\
2 \mathrm{~h} \text { or in } \\
\mathrm{Ar}+4 \% \mathrm{H}_{2} \\
\text { at } 500^{\circ} \mathrm{C}, 2 \mathrm{~h}\end{array}$ & White et al., 1993 \\
\hline $\begin{array}{l}\mathrm{Al}_{2} \mathrm{O}_{3} \\
\text { crystal }\end{array}$ & $\begin{array}{l}25 \\
30\end{array}$ & $(0.2-2.0) \cdot 10^{17}$ & & & Steiner et al., 1998 \\
\hline $\begin{array}{l}\mathrm{Al}_{2} \mathrm{O}_{3} \\
\text { crystal }\end{array}$ & 30 & $3.8 \cdot 1017$ & $3,6,10$ & & $\begin{array}{l}\text { Ganeev et al., 2005, } \\
2006\end{array}$ \\
\hline $\begin{array}{l}\mathrm{Al}_{2} \mathrm{O}_{3} \\
\text { crystal }\end{array}$ & 160 & $(0.1-1.0) \cdot 10^{17}$ & & & Marques et al., 2006 \\
\hline $\begin{array}{l}\text { ABSG, } \\
\text { BPYR } \\
\text { glasses }\end{array}$ & 270 & $1.5 \cdot 10^{16}$ & & & $\begin{array}{l}\text { Mazzoldi et al., } \\
1993\end{array}$ \\
\hline $\begin{array}{l}\mathrm{MgO} \\
\text { crystal } \\
(100)\end{array}$ & $1.5 \cdot 10^{3}$ & $1.2 \cdot 10^{17}$ & $2-3$ & $\begin{array}{l}\text { Annealing in } \\
\text { air at } 550 \text { and } \\
1100^{\circ} \mathrm{C}\end{array}$ & $\begin{array}{l}\text { Qian et al., 1997, } \\
\text { Zimmerman et al., } \\
1997\end{array}$ \\
\hline $\begin{array}{l}\mathrm{MgO} \\
\text { crystal } \\
(100)\end{array}$ & 600 & $1.0 \cdot 10^{16}$ & & $\begin{array}{l}\text { Annealing in } \\
\text { air at } 1200^{\circ} \mathrm{C} \text {, } \\
22 \mathrm{~h}\end{array}$ & $\begin{array}{l}\text { van Huis et al., } \\
2002\end{array}$ \\
\hline $\begin{array}{l}\mathrm{MgO} \\
\text { crystal } \\
(100)\end{array}$ & 200 & $2.0 \cdot 10^{17}$ & 2 & $\begin{array}{l}\text { Some samples } \\
\text { annealed in } \\
\text { air, } \mathrm{Ar}, \mathrm{O}_{2} \text { or } \\
70 \% \mathrm{~N}_{2}+30 \% \mathrm{H}_{2} \\
\text { at } 300-900^{\circ} \mathrm{C} \text {, } \\
\text { lh }\end{array}$ & Xiao et al., 2008 \\
\hline $\begin{array}{l}\mathrm{MgOP}_{2} \mathrm{O}_{5} \\
\text { glass }\end{array}$ & 150 & $(0.1-1.0) \cdot 10^{17}$ & $0.5-3$ & & $\begin{array}{l}\text { Matsunami \& \& } \\
\text { Hosono, 1993a }\end{array}$ \\
\hline $\begin{array}{l}\text { Lithia- } \\
\text { alumina- } \\
\text { silica glass }\end{array}$ & $275-285$ & $1.0 \cdot 10^{16}$ & $1-2$ & & $\begin{array}{l}\text { Arnold \& Borders, } \\
1977\end{array}$ \\
\hline $\begin{array}{l}\mathrm{LiNbO}_{3} \\
\text { crystal. } \\
\mathrm{LiNbO}_{3} \\
\text { crystal. }\end{array}$ & $\begin{array}{c}50 \\
360 \\
20,25 \\
3 \cdot 10^{3} \\
4.2 \cdot 10^{3}\end{array}$ & $\begin{array}{l}(4.0-0.8) \cdot 10^{16} \\
(0.5-8.0) \cdot 10^{16}\end{array}$ & $1-4$ & $\begin{array}{l}\text { Annealing in } \\
\text { at } 650^{\circ} \mathrm{C}, 30 \mathrm{~min} \\
\text { Some samples } \\
\text { annealed in air } \\
\text { at } 200-600^{\circ} \mathrm{C} \text {, } \\
1-3 \mathrm{~h}\end{array}$ & $\begin{array}{l}\text { Rahmani et al., } \\
1988,1989 \\
\text { Deying et al., } 1994 \\
\text { Shang et al., } 1996 \\
\text { Saito \& Kitahara, } \\
2000\end{array}$ \\
\hline
\end{tabular}




\begin{tabular}{|c|c|c|c|c|c|}
\hline $\mathrm{LiNbO}_{3}$ & 160 & $2.0 \cdot 10^{16}$ & & As implanted & Sarkisov et al. \\
\hline crystal. & $1.5 \cdot 10^{3}$ & $\begin{array}{l}4.0 \cdot 10^{16} \\
1.7 \cdot 10^{17}\end{array}$ & & $\begin{array}{l}\text { and annealing } \\
\text { in air at } 500- \\
800^{\circ} \mathrm{C}, 1 \mathrm{~h}\end{array}$ & $\begin{array}{l}\text { 1998a, 1998b, 1998c, } \\
\text { 1998d, 1999, 2000, } \\
\text { Williams et al., } \\
\text { 1998a, 1998b, } 1999\end{array}$ \\
\hline $\begin{array}{l}\mathrm{LiNbO}_{3} \\
\text { crystal. }\end{array}$ & $1.5 \cdot 10^{3}$ & $2.0 \cdot 10^{16}$ & & $\begin{array}{l}\text { Annealing in } \\
\mathrm{Ar} \text { at } 100- \\
1100^{\circ} \mathrm{C}, \\
30 \mathrm{~min}\end{array}$ & Amolo et al.; 2006 \\
\hline $\begin{array}{c}\mathrm{SiO}_{2} \\
\text { crystal. }\end{array}$ & 200 & $(2.3-9.0) \cdot 10^{16}$ & $1-5$ & $\begin{array}{l}\text { Annealing in } \\
\text { air at 300- } \\
500^{\circ} \mathrm{C} \text {, } \\
30 \mathrm{~min}\end{array}$ & $\begin{array}{l}\text { Rahmani \& \& } \\
\text { Townsend, } 1989\end{array}$ \\
\hline $\mathrm{SiO}_{2}$ & $\begin{array}{c}65 \\
130 \\
270\end{array}$ & $(1.5-5.0) \cdot 10^{16}$ & $\begin{array}{c}1 \\
1.5\end{array}$ & $\begin{array}{l}\text { Some samples } \\
\text { annealed in air } \\
\text { or } 4 \% \mathrm{H}_{2}\end{array}$ & $\begin{array}{l}\text { Mazzoldi et al., } \\
\text { 1993, Mazzoldi \& } \\
\text { Mattei, 2007, } \\
\text { Antonello et al., } \\
\text { 1998, Battaglin et } \\
\text { al., 1998, 2001, } \\
\text { Bertoncello et al., } \\
\text { 1998, Caccavale, } \\
\text { 1998, Cattaruzza et } \\
\text { al., 1999, Gonella et } \\
\text { al., 1999, Osborne, } \\
\text { 1998 }\end{array}$ \\
\hline $\mathrm{SiO}_{2}$ & 150 & $(0.1-6.0) \cdot 10^{17}$ & $1.5-14$ & & $\begin{array}{l}\text { Matsunami } \quad \& \\
\text { Hosono, 1993b }\end{array}$ \\
\hline $\mathrm{SiO}_{2}$ & 305 & $(3.0-9.0) \cdot \cdot 10^{16}$ & 2 & & $\begin{array}{l}\text { Magruder III et al., } \\
\text { 1994, 1995, 1996, } \\
\text { 2009, Anderson et } \\
\text { al., 1996, 1997, 1998, } \\
\text { 2000, Zuhr et al., } \\
1998\end{array}$ \\
\hline $\mathrm{SiO}_{2}$ & $\begin{array}{c}20-58 \\
130\end{array}$ & $(0.4-2.0) \cdot 10^{17}$ & 0.6 & & Pham et al., 1997 \\
\hline $\begin{array}{c}\mathrm{SiO}_{2} \\
\text { crystal. }\end{array}$ & 200 & $(2.3-9.0) \cdot 10^{16}$ & & & $\begin{array}{l}\text { Liu et al., 1998a, } \\
\text { 1998b, 1998c, } 2000\end{array}$ \\
\hline $\mathrm{SiO}_{2}$ & $1.5 \cdot 10^{3}$ & $\begin{array}{l}2.0 \cdot 10^{16} \\
4.0 \cdot 10^{16} \\
1.4 \cdot 10^{17}\end{array}$ & 2 & $\begin{array}{l}\text { Annealing in } \\
\text { Ar gas at } 500- \\
1000^{\circ} \mathrm{C}, 1 \mathrm{~h}\end{array}$ & Ila et al., 1998 \\
\hline $\mathrm{SiO}_{2}$ & 65 & $5.0 \cdot 10^{16}$ & & & $\begin{array}{l}\text { D'Acapito } \quad \& \\
\text { Zontone, } 1999\end{array}$ \\
\hline $\mathrm{SiO}_{2}$ & 60 & $4.0 \cdot 10^{16}$ & 10 & & $\begin{array}{l}\text { Stepanov et al. } \\
2000 b, 2003 b\end{array}$ \\
\hline $\mathrm{SiO}_{2}$ & 43 & $(0.06-$ & $1-2.5$ & Some samples & Jiang et al., 2000, \\
\hline
\end{tabular}




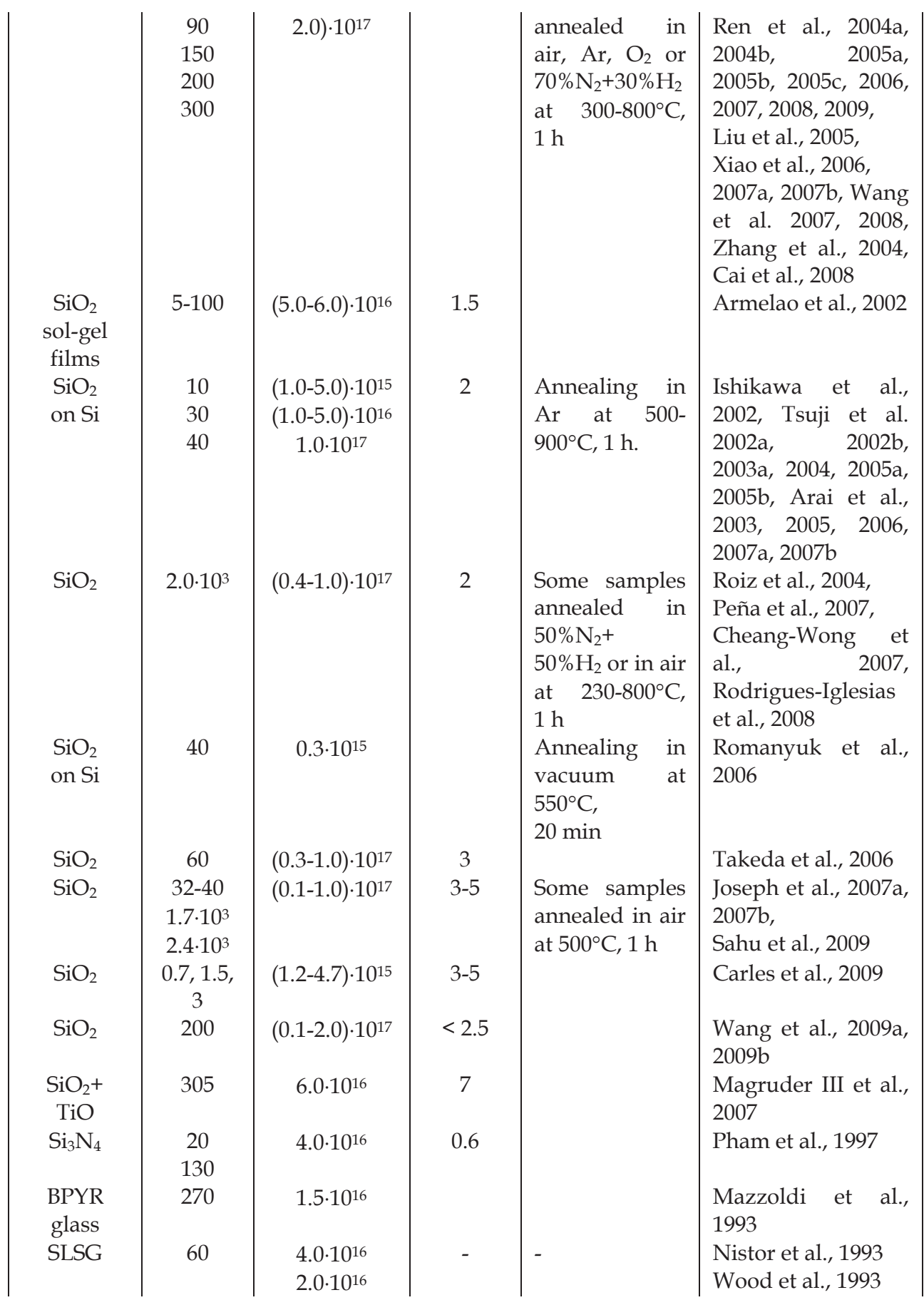




\begin{tabular}{|c|c|c|c|c|c|}
\hline SLSG & 200 & $(0.5-4.0) \cdot 10^{16}$ & $0.5-2$ & - & $\begin{array}{l}\text { Dubiel et al., 1997, } \\
2000,2003,2008\end{array}$ \\
\hline SLSG & 60 & $(2.0-7.0) \cdot 10^{16}$ & 10 & $\begin{array}{l}\text { Some samples } \\
\text { annealed in at } \\
350^{\circ} \mathrm{C}, 3 \mathrm{~h}\end{array}$ & $\begin{array}{l}\text { Stepanov et al., } \\
\text { 1998, 1999a, 1999b, } \\
\text { 1999c, 2000a, 2000b, } \\
\text { 2000c, 2001a, 2001b, } \\
\text { 2001c, 2002a, 2002b, } \\
\text { 2002c, 2002b, 2003a, } \\
\text { 2003b, 2003c, 2004a, } \\
\text { 2004b,2005b, 2008a, } \\
\text { 2008b, 2009a, 2009 } \\
\text { Hole et al. 1999 } \\
\text { Ganeev at al. 2003a, } \\
\text { 2003b,2004a, 2004b, } \\
\text { 2004c }\end{array}$ \\
\hline $\mathrm{Ta}_{2} \mathrm{O}_{5}$ & $80-130$ & $6.0 \cdot 1016$ & $0.6-6.4$ & & Pham et al., 1997 \\
\hline $\begin{array}{l}\mathrm{TiO}_{2} \\
\text { crystal }\end{array}$ & $\begin{array}{l}50 \\
65\end{array}$ & $(0.3-1.0) \cdot 10^{17}$ & 2 & $\begin{array}{l}\text { Annealing in } \\
\text { Ar at } 400^{\circ} \mathrm{C}, 1 \mathrm{~h}\end{array}$ & $\begin{array}{l}\text { Tsuji et al., 2002c, } \\
2003 b\end{array}$ \\
\hline $\begin{array}{l}\mathrm{TiO}_{2} \\
\text { sol-gel } \\
\text { films }\end{array}$ & $\begin{array}{l}30 \\
65\end{array}$ & $(0.1-0.5) \cdot 10^{17}$ & 2 & $\begin{array}{l}\text { Annealing in } \\
\mathrm{Ar} \text { at 300- } \\
600^{\circ} \mathrm{C}, 1 \mathrm{~h}\end{array}$ & $\begin{array}{l}\text { Tsuji et al., 2005c, } \\
2006\end{array}$ \\
\hline
\end{tabular}

Table 1. Types of dielectric inorganic matrix with silver nanoparticles fabricated by ion implantation combined with post-implantation heat treatment. (Abbreviations - ANZT glass, $2 \mathrm{Ag}_{2} \mathrm{O} \cdot 3 \mathrm{Na}_{2} \mathrm{O} \cdot 25 \mathrm{ZnO} \cdot 70 \mathrm{TeO}_{2} ; \mathrm{ABSG}$, alkali-borosilicate glass, $0.2 \mathrm{~K} 2 \mathrm{O} \cdot 0.8 \mathrm{~B}_{2} \mathrm{O}_{3} \cdot 3 \mathrm{SiO}_{2}$; BPYR - borosilicate Pyrex glass; SLSG, soda-lime silicate glass).

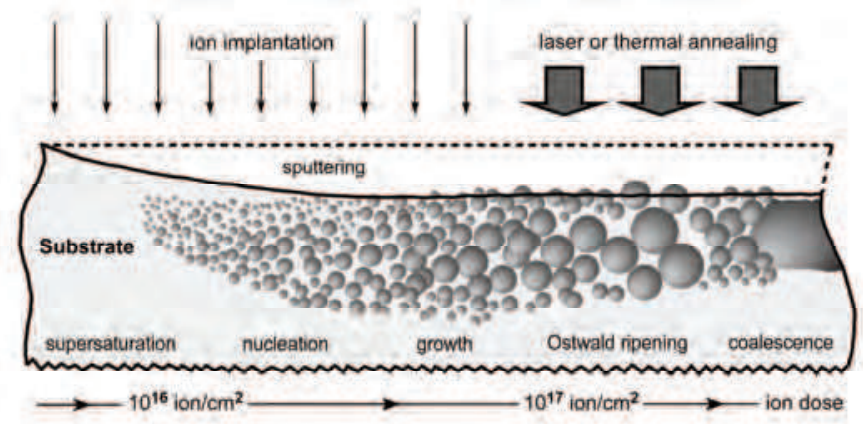

Fig. 2. Basic physical processes (from left to right) involved in the formation of nanoparticle from an implant vs. the ion dose with regard to surface sputtering under irradiation.

The range of high-dose implantation may be divided into two characteristic dose subranges. In the range $10^{15} \leq \sim F_{0} \leq 10^{17} \mathrm{ion} / \mathrm{cm}^{2}$, the concentration of $\mathrm{Ag}$ ions exceeds the solubility limit of metal atoms in matrices and the system relaxes by nucleation and growth of MNPs (Fig. 2), as illustrated in plane (Carles, et al. 2009) and cross-section (Ren, et al., 2007) transmission electron microscopy (TEM) views of $\mathrm{SiO} 2$ glass with ion-synthesized $\mathrm{Ag}$ particles (Fig. 3 and 4). The threshold dose value (at which MNPs nucleate) depends on the 
type of the dielectric matrix and implant. For example, for 25-keV Ag+-ion implantation into $\mathrm{LiNbO}_{3}$, the threshold dose was found to be $F_{0} \sim 5.0 \cdot 10^{15} \mathrm{ion} / \mathrm{cm}^{2}$ (Deying, et al. 1994), for 30-keV silver ions embedded in epoxy glass, F0 1016 ion/cm2 (Stepanov et al., 1995). The next subrange of high-dose implantation,

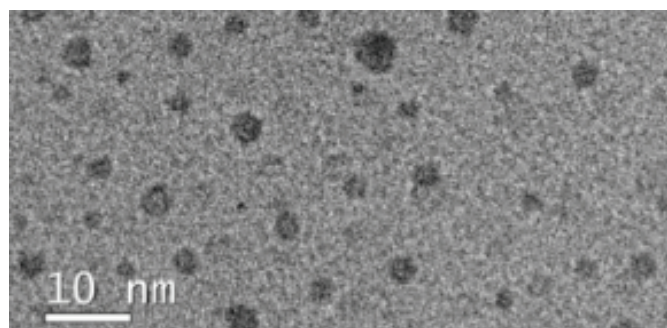

Fig. 3. Plan-view TEM image of $\mathrm{SiO}_{2}$ with $\mathrm{Ag}$ nanoparticles fabricated at a dose of $6.0 \cdot 10^{16} \mathrm{ion} / \mathrm{cm}^{2}$ and an energy of $3 \mathrm{keV}$. Fragment from (Carles, et al. 2009).

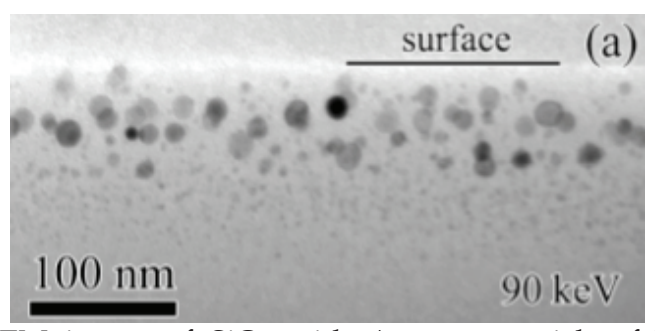

Fig. 4. Cross-section TEM image of $\mathrm{SiO}_{2}$ with $\mathrm{Ag}$ nanoparticles fabricated at a dose of $5.0 \cdot 1016 \mathrm{ion} / \mathrm{cm}^{2}$ and an energy of $90 \mathrm{keV}$. Fragment from (Ren, et al., 2007).

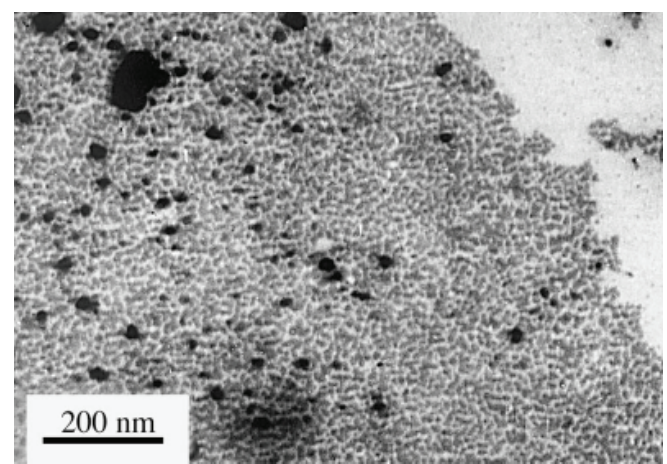

Fig. 5. Plan-view TEM image of silicone polymer-glass with Ag nanoparticles fabricated at a dose of $3.0 \cdot 10^{16} \mathrm{ion} / \mathrm{cm}^{2}$ and an energy of $30 \mathrm{keV}$. Fragment from (Khaibullin, et al. 1999).

$\sim F_{0} \geq 10^{17}$ ion $/ \mathrm{cm}^{2}$, leads to the coalescence of already existing MNPs with the formation of either MNP aggregates or thin quasi-continuous films at the dielectric surface. For instance, the irradiation of silicone polymer-glass by $30-\mathrm{keV} \mathrm{Ag}$ ions at higher-than thresholdnucleation doses favors the formation of aggregate structures (Fig. 5) (Khaibullin, et al. 
1999). The MNP distribution established in the dielectrics after coalescence or Ostwald ripening may be dramatically disturbed by postimplantation thermal or laser annealing.

\section{Laser annealing of glasses with silver nanoparticles}

Despite advantages the use of ion implantation for nanoparticle synthesis there have not yet emerged clear mechanisms which allow precisely controlled particles sizes and depth distributions. Latter has a certain drawback, which is the statistically nonuniform depth of penetration of implanted ions into a material (Stepanov et al., 2000d). This leads to a wide size distribution of synthesized nanoparticles not only in the plane parallel to the irradiated surface but to a great extent also over the depth of the sample (Nistor et al., 1993). Dispersion of nanoparticles with respect to sizes leads to a broadening of the SPR optical absorption band accompanied by a decrease it in the intensity (Kreibig \& Vollmer, 1995). This is also attributable to the dependence of the SPR spectral position on the particle size, i.e. the absorption spectrum in real sample is a superposition of several overlapping less intense bands that corresponding to particles of various sizes. The concern of the modern task is to increase the uniformity of the size distribution of MNPs synthesized by ion implantation using an approach of high-power pulse laser annealing with sequential furnace one. Experience gained from using the laser annealing techniques for various purposes allowed MNPs to be modified in various dielectrics. The main feature most of all the experiments with laser annealing of composites with MNPs is that the laser light was applied directly into the spectral region of the transparency of the dielectric matrix, and consequently, the intense laser pulses were primarily absorbed by the metal particles. Contrary to that, a new approach for annealing was demonstrated, when SLSG with Ag particles was irradiated by a laser light at wavelengths of glass absorption in the ultraviolet region (Wood et al., 1993). When applying high-power excimer ArF (193 nm) laser pulses, a decrease of the reflectance intensity of composite samples was observed. It was suggested that the implanted silver particles in glass can be dissolved and the glass matrix can be modified to be a silver rich metastable new glass phase. If this is correct then the new phase will be the potential to be destabilized to precipitate out the new silver particles in a controlled fashion by furnace.

As seen in Fig. 6 at low energy implantation the silver depth concentration in the SLSG derived from experimental Rutherford backscattering spectrometry (RBS) spattering shows a maximum near the implanted surface of the sample with some penetration to about 60$65 \mathrm{~nm}$ (Stepanov et al., 1999a). 


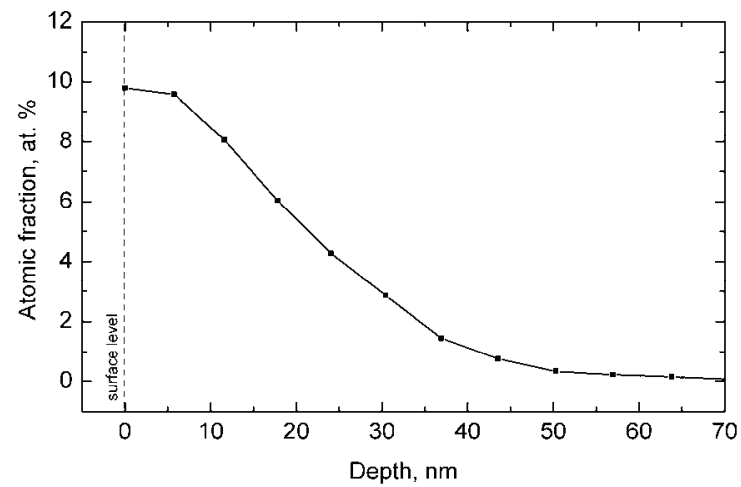

Fig. 6. The depth distribution of silver derived from the RBS spectrum for ion implantation with a dose of 7 $10^{16} \mathrm{ion} / \mathrm{cm}^{2}$ and an energy of $60 \mathrm{keV}$ into the SLSG.

An excess of metal atoms in the glass, above the solubility limit, causes nucleation of the nanoparticles. As usually the size distribution of MNPs appears. Additional to this distribution in the implanted sample there is distribution particles in the depth. Since the increase of metal concentration in the depth profile and the sputtering yield depend on implantation time, then the metal particle nucleation and growth will also vary with time and depth. It is obvious that during the implantation the size of the growthing particles with depth is "proportional" to the metal filling factor, because they are both determined by the ion concentration profile. Consequently, according to the Fig. 6 the large silver nanoparticles (or/and the higher filling factor) in the glass are close to the implanted surface with small ones in the interior of the implant zone. These features can be recognized in optical spectra of dielectrics with implanted nanoparticles. As example, transmittance and reflectance data of the non-implanted and implanted glass are presented in Fig. 7 (Stepanov et al., 1999a).

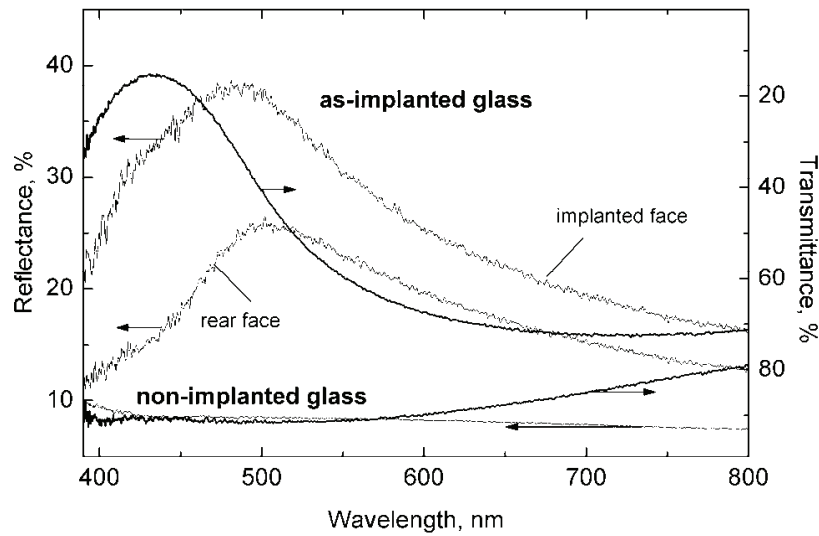

Fig. 7. Optical transmittance and reflectance of the silver implanted and original SLSG with a dose of $7 \cdot 10^{16} \mathrm{ion} / \mathrm{cm}^{2}$ and an energy of $60 \mathrm{keV}$. Reflectance was measured from both the implanted and rear faces of the sample. 
The transmission spectrum of implanted glass is maximized near $430 \mathrm{~nm}$ and the shape of the spectral curve is almost symmetrical. The reflectance spectra of same sample are more complex and, although the transmission must be the same whether the glass is viewed from the implanted or the reverse face, the shapes of the reflectivity curves differ. Overlapping peaks of reflectance spectra measured from the implant face of the samples exhibit a shoulder at about $430 \mathrm{~nm}$, on the side of a clearly determined maximum at $490 \mathrm{~nm}$, whereas reflectivity from the rear face appears to have a simpler peak at longer wavelengths near $500 \mathrm{~nm}$. The contrast between the spectrum available from transmittance and reflectance of the implanted glass is recognized as coming from the non-uniform silver profile and size distribution of the nanoparticles in the implanted glass (Fig. 6). Since the distribution pattern is not symmetric, the reflectivity determined from the ion implanted and rear faces of the sample differ (Fig. 7), and the reflected intensity from a particular layer depends on the their local absorption in the depth. The atomic force microscope (AFM) images implanted surfaces of the same samples shown in Fig. 8 (Stepanov et al., 1998). As seen from the figure the implanted surface is smoother (roughness) and there are many hemispherical hills on this surface with an average diameter of approximately 100-150 nm. There are no such protrusions on the unimplanted sample. The reason for the existence of

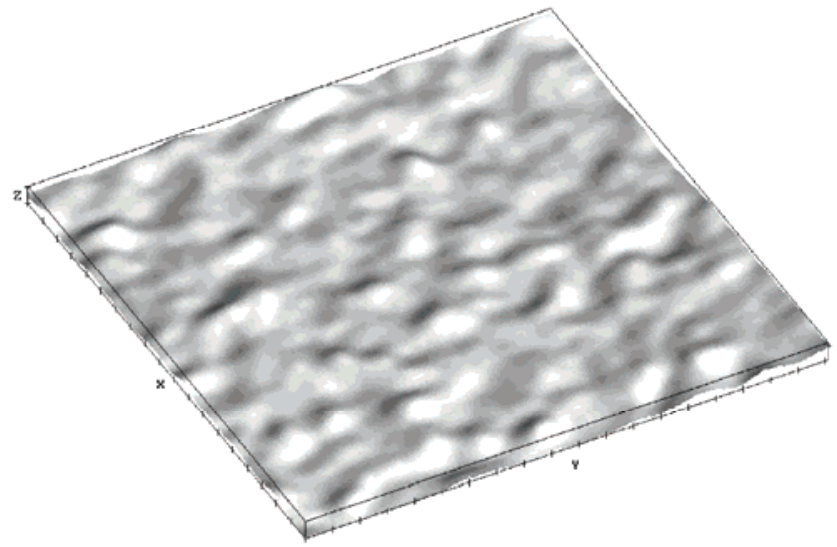

Fig. 8. An AFM image as a top view under lateral illumination of the surface of SLSG Agimplanted with a dose of $7 \cdot 10^{16} \mathrm{ion} / \mathrm{cm}^{2}$ and an energy of $60 \mathrm{keV}$. The step along the $X$ and $\mathrm{Y}$ axes id $100 \mathrm{~nm}$, and the step along the $\mathrm{Z}$ axis is $3 \mathrm{~nm}$.

surface hills is assumed to be from a sputtering of irradiated glass during implantation, which leads to unequal ejection of ions of different elements from the surface, exposing the synthesized nanoparticles in the sub-surface glass. The sputtered glass thickness is typically of the order of tens of nanometers for the present ion dose (Hole et al., 1998), and hence, the synthesized buried MNPs appear near to the glass surface in the implanted sample.

Consequences of the excimer laser pulse with nanosecond pulse width and high beam intensity are heating, melting and/or vaporisation (ablation) of material on a time scale of nanoseconds to microseconds. The excimer laser treatment has been applied to many glasses, but there is less information on high-power pulse laser interaction with dielectrics containing metal nanoparticles. In the present case the energy density is lower than the value of the ablation threshold for the SLSG, which was determined to be about $5 \mathrm{~J} / \mathrm{cm}^{2}$ 
(Buerhop et al., 1990). Also, the excimer laser is characterised by a UV-wavelength, which is much longer than the typical sizes of the nanoparticles formed by ion implantation. Hence, present metal/glass composites may be considered similar to be a homogeneous material for light propagation (Kreibig \& Vollmer, 1995). This is a simplification, which is true generally for low intensity light, but it gives an estimate of the optical penetration depth as $\left(\alpha^{-1}\right)$ of the laser pulses into the composite material, where $\alpha$ is the linear absorption coefficient. An intense laser pulse is absorbed and relaxed into heat into the surface SLSG layer of a thickness of $\alpha^{-1}$, which is several microns (Townsend \& Olivares, 1997), i.e., deeper than the thickness of the implanted layer (Fig. 6).

The optical spectral result of pulse laser treatment by 5 pulses of a $\mathrm{KrF}$ excimer laser with pulse length of $25 \mathrm{~ns}$ full-width at half-maximum at a wavelength of $248 \mathrm{~nm}$ with the total released energy of $0.2 \mathrm{~J} / \mathrm{cm}^{2}$ on the optical spectra of the Ag-implanted glass is presented in Fig. 9 (Stepanov et al., 2001). Applied laser pulses did not change the reflectance and transmittance spectra of the non-implanted SLSG, but for implanted sample the location of the transmittance minimum shifts slightly towards shorter wavelengths, and the transmittance in peak position increases from 16 to 23\% (Fig. 9a). Remarkable change was found in the reflectance spectra, where in the case of the implanted surface, the peak of the overlapping bands shifts continuously from 490 to $450 \mathrm{~nm}$ with modifications in the

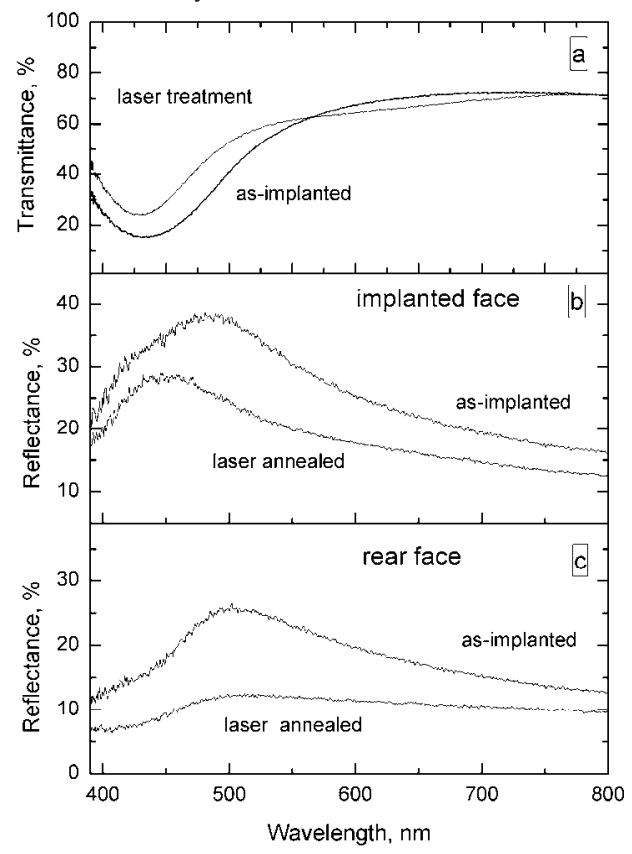

Fig. 9. Optical spectra of the SLSG after silver implantation as in Fig. 7 and the implantation followed with laser treatment $\left(0.2 \mathrm{~J} / \mathrm{cm}^{2}\right)$ : (a) transmittance; (b) reflectance measured from the implanted face; (c) reflectance measured from rear faces of the sample.

shape of the envelope of the bands, which become narrower (Fig. 9b). The reflectance intensity falls from 38 to $27 \%$. However, for reflectance from the rear face of the same 
sample (Fig. 9c) there is only a decrease of the intensity to a $13 \%$ maximum, which is at the same initial wavelength as in the implanted sample.

For composite materials with MNPs effective-medium theories (Maxwell-Garnett, Bruggeman, etc) can be considered (Kreibig \& Vollmer, 1995). According to this approach, the measured optical intensities corresponding to the implanted glass (Figs. 7 and 9) are determined mainly by the near-surface layer, where there is the largest metal filling factor, and also the largest nanoparticles. The smaller filling factors (and smaller nanoparticles) that exist at the other depths effectively only influence a smearing of the optical spectra. Moreover, consistent with effective-medium considerations, a decrease of the filling factor is accompanied by movement of the optical peak position to shorter wavelengths, as is observed in Fig. 9. Thus, a decrease of the filling factor in the composite resulting from laser treatment suggests there is a size reduction of all the silver nanoparticles, and again the biggest nanoparticles are localized near the SLSG surface. The difference between reflectance spectra from implanted and rear faces of laser treated sample (Fig. 9 b, c) emphasizes the existence of a non-symmetrical depth distribution of the Ag nanoparticles as being similar to the distribution in the implanted sample.

As presented in Fig. 10, (note an increased magnification of ten times in the direction perpendicular to plane of the figure), it is seen that there are a lot of clearly defined hills

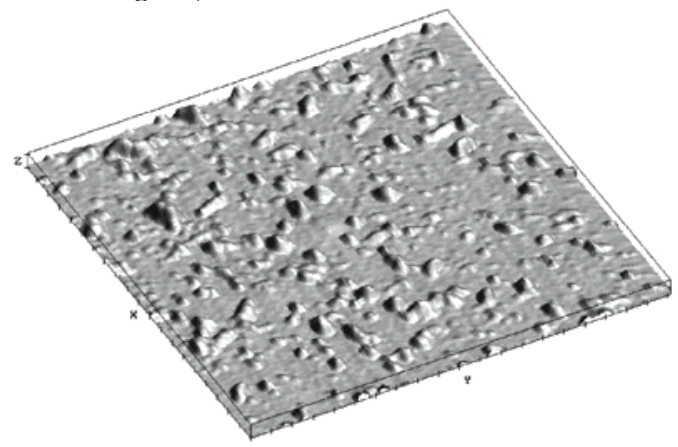

Fig. 10. An AFM image as a top view under lateral illumination of the surface of SLSG Agimplanted with a dose of 7.1016 ion/ $\mathrm{cm}^{2}$ and an energy of $60 \mathrm{keV}$ followed with irradiation with an excimer laser $\left(0.2 \mathrm{~J} / \mathrm{cm}^{2}\right)$. The step along the $X$ and $Y$ axes id $100 \mathrm{~nm}$, and the step along the $\mathrm{Z}$ axis is $40 \mathrm{~nm}$.

(believed to be silver particles) on the glass surface whose size is one order smaller in contrast to large hills on the implanted glass surface in Fig. 8 (Stepanov et al., 1998). The Ag MNPs accumulate effect on the laser irradiated surface of glass is result of melting implanted composite layer and some desorption of glass material under the laser pulses, which exposes the melted metal particles after their solidification. Hence, the first of the conclusions from the present data on excimer laser treatment of implanted glass is the reduction of the size of the silver nanoparticles, and second is the existence of some asymmetry in their depth distribution (Fig 9b, c). To recognize the mechanisms by which the changes occur for strongly absorbed excimer laser pulses the thermal propagation after the laser-irradiation must be considered. The laser heating is traditionally characterized by the heat diffusion length, $l(t)=(D \cdot t)^{1 / 2}$, where $D$ is the heat diffusivity, and $t$ is the laser pulse duration. In the present experiment with laser pulses of $25 \mathrm{~ns}$, the heat propagation is 
approximately $l(t)=115 \mathrm{~nm}$, that is shorter than the $\alpha^{-1}$, i.e., the temperature rise is no longer controlled by the diffusion of the heat. However, the $l(t)$ surpasses the depth of the implanted Ag nanoparticles. As was estimated earlier (Townsend \& Olivares, 1997), the temperature at the surface of laser treated SLSG reaches values exceeding $\sim 700^{\circ} \mathrm{C}$, which is equivalent to the SLSG melting temperature. Under these temperature conditions there is also a possibility for melting small silver particles, because their melting temperature is drastically decreased, for example, to $\sim 400^{\circ} \mathrm{C}$ for sizes $<30 \mathrm{~nm}$, compared with the bulk metal melting temperature of $960^{\circ} \mathrm{C}$ (Castro et al., 1990). The time scale of electronic relaxation and energy transfer to the lattice vibrations in the metal particles is several orders faster than in the surrounding glass medium. Therefore, during the interaction of the excimer laser pulse with the metal/glass composite, the Ag nanoparticles are heated and melted more quickly than solidification of the melted glass can occur. Atomically dispersed Ag released from nanoparticles enters into the glass melt, and immediately diffuse throughout all the heated thickness of the laser treated substrate. In principle in time this could lead to a uniform metal distribution, where the silver atom concentration exceeds the solubility value in the solid glass. However, following glass solidification spreading from the depth to the surface, as heat from the laser pulse penetrates into the depth of the sample, the cooling part of the annealing cycle will stimulate new nucleation and regrowth of metal particles. In this case, the possibility of regrowth of metal particles will depend on competition between regrowth and the cooling speed of the moving solidification front, resulting in a new non-uniform size distribution of new MNPs over a depth scale similar to that after ion implantation. Obviously, under some conditions the metal particles may be dispersed into separate metal ions and/or into such small units that they cannot display nanoparticle type optical properties. As shown here, subsequent high power excimer laser pulse treatments of the ion implanted layer may be used to melt, and/or regrow, the MNPs within the insulator medium. Overall this results in a tighter distribution of small particles. The laser treatments have slightly reduced, but not completely removed evidence for a nonsymmetric depth distribution of the silver particles. The Ag-insulator composite material is complex, and so a much wider range of laser pulse conditions, and more data on the cooling rates are required to fully model the changes in the size distributions, which can occur.

\section{Nonlinear optical properties of ion-synthesized silver nanoparticles}

The Ag nanoparticles doped in different dielectrics demonstrate variable nonlinear optical properties (Palpant, 2006). The interest on such structures is based on the prospects of the elaboration of optical switchers with ultrafast response, optical limiters, and intracavity elements for mode locking. Ag nanoparticles have an advantage over another metal nanoparticles (i.e., gold and copper) from the point of view that the surface plasmon resonance energy of $\mathrm{Ag}$ is far from the interband transition energy. So, in the silver nanoparticle system it is possible to investigate the nonlinear optical processes caused solely by SPP contribution. It should be noted that previous studies of nonlinear optical parameters of silver nanoparticles-doped glasses were mostly focused on determination of third-order nonlinear susceptibility $\chi^{(3)}$. The saturated absorption in silicate glasses doped with Ag nanoparticles at wavelength of $532 \mathrm{~nm}$ and their dependence on laser radiation intensity are considered at present review. 
The Ag nanoparticles ion-synthesized in SLSG (Ag:SLSG) and (Ag:SiO ${ }_{2}$ demonstrate the SPP band with minimum transmission in the range of 410-440 nm (Fig. 11).

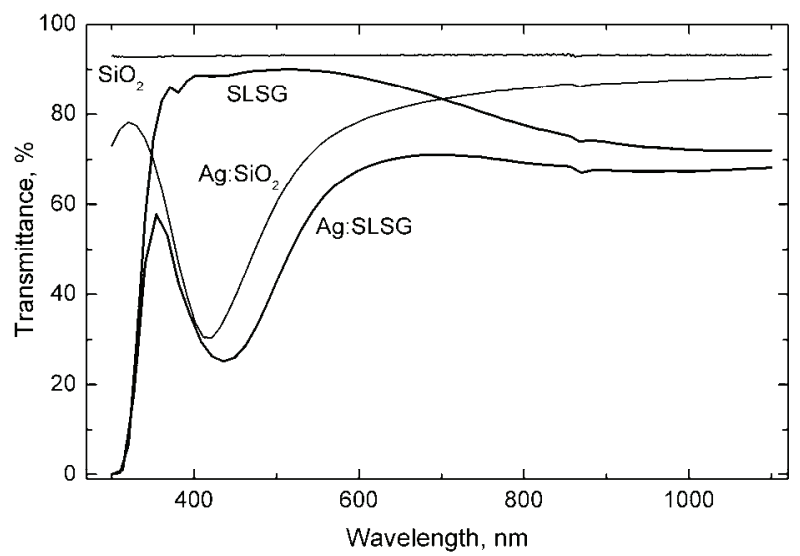

Fig. 11. Optical transmittance of the $\mathrm{Ag}$ nanoparticles formed in SLSG and $\mathrm{SiO}_{2}$ by implantation with a dose of $4 \cdot 10^{16} \mathrm{ion} / \mathrm{cm}^{2}$ and an energy of $60 \mathrm{keV}$.

It was previously predicted that silver-doped glasses possess by saturated absorption. The spectral dispersion of the imaginary part of third-order susceptibility $\operatorname{Im} \chi^{(3)}$ of silver-doped glass matrices was analyzed and it was shown that $\operatorname{Im} \chi^{(3)}$ was negative in the spectral range of $385-436 \mathrm{~nm}$ (Hamanaka et al., 2000). The nonlinear absorption coefficient $\beta$ is also negative in the case of saturated absorption.

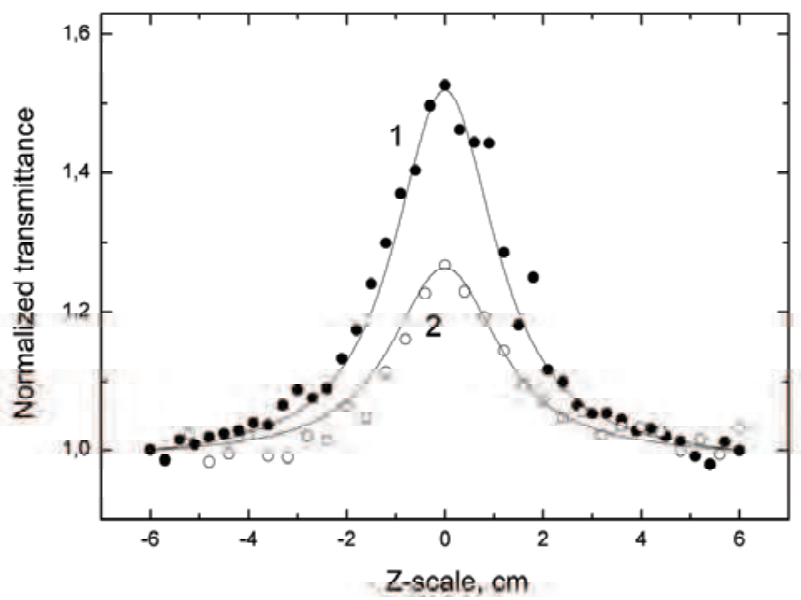

Fig. 12. Normalised transmittance Ag:SLSG (1) and Ag:SiO 2 (2) samples at laser radiation intensity of $I_{0}=2.5 \cdot 10^{9} \mathrm{~W} / \mathrm{cm}^{2}$. Solis lines show theoretical fittings.

The normalized transmittance dependences of Ag:SLSG and Ag:SiO 2 samples measured using open aperture Z-scan scheme (Sheik-Bahae et al., 1990) at laser radiation intensity of 
$I_{0}=2.5 \cdot 10^{9} \mathrm{~W} / \mathrm{cm}^{2}$ and pulse duration of $55 \mathrm{ps}$ is presented in Fig. 12. The transmission of samples was increased due to saturated absorption as they approached close to the focal plane. The theoretical fitting was done by the method described early (Ganeev et al., 2004b). After fitting of experimental data the $\beta$ are $-6.7 \cdot 10^{-5} \mathrm{~cm} / \mathrm{W}$ in Ag:SLSG and $-3.6 \cdot 10^{-5} \mathrm{~cm} / \mathrm{W}$ in Ag:SiO 2 . Coefficient $\beta$ can be presented as $\beta=\alpha / I_{\mathrm{s}}$ where is $I_{\mathrm{s}}$ saturated intensity. The values of $I_{\mathrm{s}}$ are $1.1 \cdot 10^{9}$ and $1.4 \cdot 10^{9} \mathrm{~W} / \mathrm{cm}^{-2}$, also the $\operatorname{Im} \chi^{(3)}$ are $-2.4 \cdot 10^{-8}$ and $-1.3 \cdot 10^{-8}$ esu in Ag:SLSG and $\mathrm{Ag}: \mathrm{SiO}_{2}$, respectively.

In Figs. 13 and 14 values of $\beta$ in dependence of laser intensity varied from $10^{9}$ to $2 \cdot 10^{10} \mathrm{~W} / \mathrm{cm}^{2}$ are presented. As seen from the figures there are a decrease $\beta$ of for higher intensities. In particularly, a 21- and 12-fold decrease of $\beta$ was measured at $I_{0}=1.15 \cdot 10^{10} \mathrm{~W} / \mathrm{cm}^{2}$ for Ag:SLSG and Ag:SG, respectively, compared to $\beta$ detected at $I_{0}=1 \cdot 10^{9} \mathrm{~W} / \mathrm{cm}^{2}$.

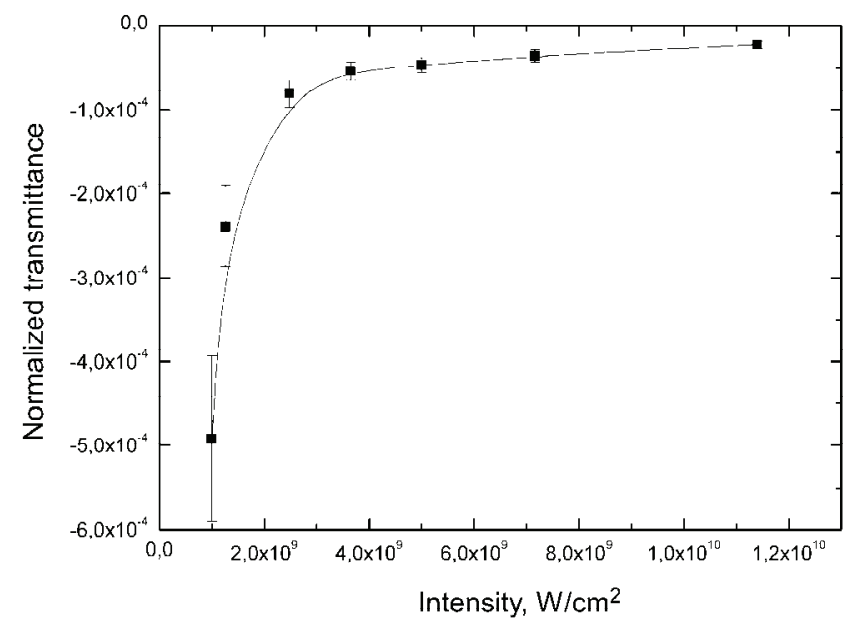

Fig. 13. Coefficient $\beta$ of Ag:SLSG in dependence of laser intensity.

The variations of transmission in similar MNP structures were attributed in some cases to the fragmentation (Kurata et al., 1998; Link et al. 1999; Mafune et al., 2002), or fusion (Chandrasekharan et al., 2000) of nanoparticles following the photothermal melting. It was reported about the alteration of the sign of nonlinear refractive index of small Ag clusters embedded in SLSG (Osborne et al., 1998). They noted that thermal effects could change the properties of nanoclusters. The transparency in these samples was associated with oxidation of Ag nanoparticles. However, no irreversible changes of transmittance were observed in present experiments. 


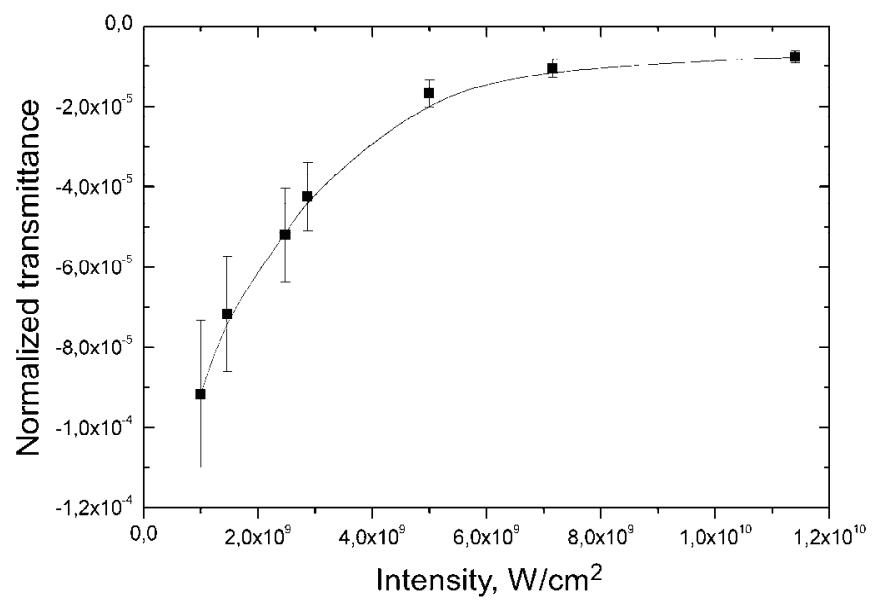

Fig. 14. Coefficient $\beta$ of $\mathrm{Ag}: \mathrm{SiO}_{2}$ in dependence of laser intensity.

The reverse saturated absorption can be responsible for the decrease of negative nonlinear absorption of Ag nanoparticles and it could be assume that in the case of picosecond pulses the reverse saturated absorption starting to play an important role in the overall dynamics of nonlinear optical transmittance of metal nanoparticles contained compounds, taking into account the saturation of intermediate transitions responsible for saturated absorption. Thus, saturated absorption in Ag:SLSG and Ag: $\mathrm{SiO}_{2}$ was dominated at small intensities and decreased with the growth of intensity due to influence of competing effects, whereas the selfdefocusing at low intensities was changed to self-focusing at high intensities. The possible mechanism of the decrease of $\operatorname{Im} \chi^{(3)}$ is the influence of nonlinear optical processes with opposite dependences on laser intensity, also such as two-photon absorption (SheikBahae et al., 1990). The wavelength range corresponded to the interband transitions in Ag is located below $320 \mathrm{~nm}$, so the two-photon absorption connected with interband transitions can be involved in the case of $532 \mathrm{~nm}$ radiation. The possibility of two-photon absorption due to interband transition of photoexcited electrons was previously demonstrated for $\mathrm{Ag}$ partilces (Magruder et al., 1994). The three-photon absorption connected with interband transition for Ag nanoparticles was analysed in (Kyoung et al., 1999). Thus, saturated absorption in Ag:SLSG and $\mathrm{Ag}: \mathrm{SiO}_{2}$ was dominated at small intensities and decreased with the growth of intensity due to influence of competing effects, whereas the selfdefocusing at low intensities was changed to self-focusing at high intensities.

\section{Acknowledgements}

Author is grateful to the Alexander Humboldt Foundation for the financial support of this work in Germany and Austrian Scientific Foundation in the frame of Lisa Meitner Fellowship. I wish to thank my partners and co-authors D. Hole, P.D. Townsend, I.B. Khaibullin, V.I. Nugdin, V.F. Valeev, R.I. Khaibullin, V.N. Bazarov, Yu.N. Osin, S.N. Abdullin, V.A. Zikharev, I.A. Faizrakhmanov, A.A. Bukharaev, V.N. Popok, U. Kreibig, A.I. Ryasnyansky, R.A. Ganeev, E. Alves. 


\section{References}

Amolo, G.O.; Comins, J.D.; Naidoo, S.R.; Connell, S.H.; Witcomb, M.J. \& Derry, T.E. (1999). Effects of $\mathrm{Ag}^{+}$and $\mathrm{Au}^{3+}$ ion implantation of lithium niobate, Nucl. Inst. Meth. Phys. Res. B 250, 233-237

Anderson, T.S.; Magruder III, R.H.; Zuhr, R.A. \& Wittig, J.E. (1996). Optical properties of multicomponent nanometer dimension metal colloids formed in silica by sequential ion implantation of $\mathrm{In}$ and $\mathrm{Ag}$ and $\mathrm{In}$ and $\mathrm{Cu}$, J. Electronic Mater. 25, 2735

Anderson, T.S.; Magruder III, R.H.; Kinser, D.L.; Zuhr, R.A. \& Thomas, D.K. (1997). Formation and optical properties of metal nanoclusters formed by sequential implantation of Cd and Ag in silica, Nucl. Inst. Meth. Phys. Res. B 124, 40-46

Anderson, T.S.; Magruder III, R.H.; Kinser, D.L.; Wittig, J.E.; Zuhr, R.A. \& Thomas, D.K. (1998). Ag:Cd and Cd:Ag implantations into high purity silica, J. Non.-Cryst. Sol. 224, 299-306

Anderson, T.S.; Magruder III, R.H.; Wittig, J.E.; Kinser, D.L. \& Zuhr, R.A. (2000). Fabrication of Cu-coated Ag nanocrystals in silica by sequential ion implantation, Nucl. Inst. Meth. Phys. Res. B 171, 401-405

Antonello, M.; Arnold, G.W.; Battaglin, G.; Bertoncello, R.; Cattaruzza, E.; Colombo, P.; Mattei, G.; Mazzoldi, P. \& Trivillin, F. (1998). Fluence and current density dependence of silver nanocluster dimensions in ion-implanted fused silica, J. Mater. Chem. 8, 457-461

Armelao, L.; Bertoncello, R.; Cattaruzza, E.; Gialanella, S.; Gross, S.; Mattei, G.; Mazzoldi, P. \& Tondello, E. (2002). Chemical and physical routes for composite materials synthesis: Ag and Ag2S nanoparticles in silica glass by sol-gel and ion implantation techniques, J. Mater. Chem. 12, 2401-2407

Arai, N.; Tsuji, H.; Motono, M.; Goto, Y.; Adachi, K.; Kotaki, H. \& Ishikawa, J. (2003). Formation of silver nanoparticles in thin oxide layer on $\mathrm{Si}$ by negative-ion implantation, Nucl. Inst. Meth. Phys. Res. B 206, 629-633

Arai, N.; Tsuji, H.; Ueno, K.; Matsumoto, T.; Gotoh, Y.; Abachi, K.; Kotaki, H. \& Ishikawa, J. (2005). Evaluation of nanoparticles emvedded in thin silicon dioxide film by optical reflection property, Surf. Coat. Technol. 196: 44-49

Arai, N.; Tsuji, H.; Ueno, K.; Matsumoto, T.; Gotoh, Y.; Abachi, K.; Kotaki, H.; Gotoh, Y. \& Ishikawa, J. (2006). Formation of silver nanoparticles aligned near the bottom of $\mathrm{SiO}_{2}$ film on silicone substrate by negative-ion implantation and post-annealing, Nucl. Inst. Meth. Phys. Res. B 242, 217-220

Arai, N.; Tsuji, H.; Abachi, K.; Kotaki, H.; Gotoh, Y. \& Ishikawa, J. (2007a). Silver negativeion implantation into thermally growth this $\mathrm{SiO}_{2}$ film on $\mathrm{Si}$ substrate and heat treatment for formation of silver nanoparticles, Jap. J. Appl. Phys. 46, 6260-6266

Arai, N.; Tsuji, H.; Gotoh, N.; Matsumoto, T.; Ishibashi, T.; Adachi, K.; Kotaki, H.; Gotoh, Y. \& Ishikawa, J. (2007b). Nanocrystal formation of metals in thermally grown thin silicon dioxide layer by ion implantation and thermal diffusion of implanted atoms in heat treatment, J. Phys.: Conf. Ser. 61, 41-45

Arnold, G.W. (1975). Near-surface nucleation and crystallization of an ion-implanted lithiaalumina-silica glass, J. Appl. Phys. 46, 4466-4473

Arnold, G.W. \& Borders, J.A. (1977). Aggregatin and migration of ion-implanted silver in lithia-alumina-silica glass, J. Appl. Phys. 48, 1488-1496 
Battaglin, G.; Cattaruzza, E.; D'Acapito, F.; Gonella, F.; Mazzoldi, P.; Mobilio, S. \& Priolo, F. (1998). EXAFS study on metal cluster doped silica glass obtained by ion implantation procedures, Nucl. Inst. Meth. Phys. Res. B 141, 252-255

Battaglin, G.; Catalano, M.; Cattaruzza, E.; D'Acapito, F.; De Julian C., Fernandez, G.; De Marchi, G.; Gonella, F.; Mattei, G.; Maurizio, C.; Mazzoldi, P.; Miotello, A. \& Sada, C. (2001). Influence of annealing atmosphere on metal and metal alloy nanoclusters produced by ion implantation in silica, Nucl. Inst. Meth. Phys. Res. B 178, 176-179

Bertoncello, R.; Gross, S.; Trivillin, F.; Cattaruzza, E.; Mattei, G.; Caccavale, F.; Mazzoldi, P. \& Battaglin, G. (1999). Mutually reactive elements in a glass host matrix: Ag and S ion implantation, J. Mater. Res. 14, 2449-2457

Buerhop, C.; Blumenthal, B. \& Weissmann, R. (1990) Glass surface treatment with excimer and $\mathrm{CO}_{2}$ laser, Appl. Surf. Sci. 46, 430-434

Caccavale, F. (1998). Metal-ion implantation in glasses: Physical and chemical aspects, Pramana - J. Phys. 50, 653-668

Cai, G.X.; Ren, F.; Xiao, X.H.; Fan, L.X. \& Jiang, C.Z. (2008). Fabrication of hallow Ag nanoclusters in silica by irradiation with Ar ions, Nucl. Inst. Meth. Phys. Res. B 266, 889-893

Carles, R.; Farcãu, C.; Bonafos, C.; Benassayag, G.; Pécassou, B. \& Zwick, A. (2009). The synthesis of single layers of Ag nanocrystals by ultra-low-energy in implantation for large-scale plasmonic structures, Nanotechnol. 20, 1-6

Castro, T.; Reifenberger, R.; Choi, E. \& Andres, R.P. (1990). Size-dependent melting temperature of individual nanometer-sized metallic clusters, Phys. Rev. B 42, 85498556

Cattaruzza, E.; Battaglin, G.; Polloni, R.; Cesca, T.; Gonella, F.; Mattei, G.; Maurizio, C.; Mazzoldi, P.; D'Acapito, F.; Zontone, F. \& Bertoncello R. (1999). Nanocluster formation in silicate glasses by sequential ion implantation procedures, Nucl. Inst. Meth. Phys. Res. B 148, 1007-1011

Chandrasekharan, N.; Kamat, P.V.; Hu, J. \& Jones II, G. (2000). Day-capped gold nanoparticles: Photoinduced morphological changes in gold/rhodamine 6G nanoassemblies, J. Phys. Chem. B 104, 11103-11109

Cheang-Wong, J.C.; Oliver, A.; Rodríguez-Fernandez, L.; Arenas-Alatorre, J.; Peña, O. \& Crespo-Sosa, A. (2007). Optical absorption and HRTEM characterization of metallic nanoparticles produced by $\mathrm{MeV}$ ion implantation, Revista Mexicana de Física S 53, 49-54

D'Acapito, F. \& Zontone, F. (1999). Grazing-incidence X-ray diffrectin in the study of metallic clusters buried in glass obtained by ion implantation, J. Appl. Cryst. 32, 234240

Davenas, J.; Perez, A. ; Thevenard, P. \& Dupuy, C.H.S. (1973). Correlation between absorption bands and implanted alkali ions in LiF, Phys. Stat. Sol. A 19, 679-686

Deying, S.; Saito, \& Y. Suganomata, S. (1994). Optical properties of $\mathrm{LiNbO}_{3}$ implanted with $\mathrm{Ag}^{+}$ions, Jpn. J. Appl. Phys. 33, L966-L969

Dubiel, M.; Hofmeister, H. \& Schurig, E. (1997). Compressive stresses in Ag Nanoparticle Doped Glasses by Ion Implantation, Phys. Stat. Sol. B 203, R5-R6

Dubiel, M.; Hofmeister, H.; Schurig, E.; Wendler, E. \& Wesch, W. (2000). On the stress state of silver nanoparticles in ion-implanted silicate glasses, Nucl. Inst. Meth. Phys. Res. B $166-167,871-876$ 
Dubiel, M.; Hofmeister, H.; Tan, G.L.; Schicke, K.-D. \& Wendler, E. (2003). Silver diffusion and precipitation of nanoparticles in glass by ion implantation, Eur. Phys. J. D 24, 361-364

Dubiel, M.; Hofmeister, H. \& Wendler, E. (2008). Formation of nanoparticles in soda-lime glasses by single and double ion implantation, J. Non.-Cryst. Solids 354, 607-611

Flytzanis, C.; Hache, F.; Klein, M.C.; Ricard, D. \& Rousignol P. (1991). Nonlinear Optics in composite materials, Elsevier Science, Amsterdam

Ganeev, R.A.; Ryasnyanskii, A.I.; Stepanov, A.L.; Kondirov, M.K. \& Usmanov, T. (2003a). Nonlinear properties of composites based on dielectric layers containing copper and silver nanoparticles, Opt. and Spectroscopy 95, 967-975

Ganeev, R.A.; Ryasnyanskii, A.I.; Stepanov, A.L. \& Usmanov, T. (2003b). Nonlinear optical susceptibilities of copper- and silver-doped silicate glasses in the ultraviolet range, Phys. Stat. Sol. B 238, R5-R7

Ganeev, R.A.; Ryasnyanskii, A.I.; Stepanov, A.L. \& Usmanov, T. (2004a). Nonlinear optical response of silver and copper nanoparticles in the near-ultraviolet spectral range, Phys. Solid. State. 46, 341-346

Ganeev, R.A.; Ryasnyanskii, A.I.; Stepanov, A.L. \& Usmanov, T. (2004b). Saturated absorption and nonlinear refraction of silicate glasses doped with silver nanoparticles at 532 nm, Opt. Quant. Electr. 36, 949-960

Ganeev, R.A.; Ryasnyanskii, A.I.; Stepanov, A.L. \& Usmanov, T. (2004c). Characterization of nonlinear optical parameters of copper- and silver-doped silica glasses at $\lambda=1064$ nm, Phys. Stat. Sol. B 241, 935-944

Ganeev, R.A.; Ryasnyanskii, A.I.; Stepanov, A.L.; Marques, C.; da Silva, R.C. \& Usmanov, T. (2005). Application of RZ-scan technique for investigation of nonlinear refraction of sapphire doped with Ag, $\mathrm{Cu}$ and Au nanoparticles, Opt. Comm. 253, 205-213

Ganeev, R.A.; Ryasnyanskii, A.I.; Stepanov, A.L.; Usmanov, T.; Marques, C.; da Silva, R.C. \& Alves, E. (2006). Investigation of the nonlinear optical characteristics of composite materials based on sapphire with silver, copper, and gold nanoparticles by the reflection Z-scan method, Opt. and Spectr. 101, 615-622

Gonella, F.; Mattei, G.; Mazzoldi, P.; Sada, C.; Battaglin, G. \& Cattaruzza E. (1999). Au-Cu nanoclusters in silica formed by ion implantation and annealing in reducing or oxidizing atmosphere, Appl. Phys. Lett. 75, 55-57

Hamanala, Y.; Hayashi, N.; Nakamura, A. \& Omni, S. (2000). Dispersion of thired-order nonlinear optical susceptibility of silver nanocrystal-glass composites, J. Luminescence 87-89, 859-861

Hole, D.E.; Stepanov, A.L. \& Townsend, P.D. (1999). Dependence of optical properties of implanted silver nanoparticles in float glass on substrate temperature, Nucl. Instrum. Meth. Phys. Res. 148, 1054-1058

van Huis, M.A.; Fedorov, A.V.; van Veen, A.; Falub, C.V., Eijt, S.W.H., Kooi, B.J.; De Hosson, J.Th.M., Hibma, T. \& Zimmerman, R.L. (2002). Structural properties of Au and Ag nanoclusters embedded in $\mathrm{MgO}, \mathrm{Nucl}$. Inst. Meth. Phys. Res. B 191, 442-446

Ila, D.; Williams, E.K.; Sarkisov, S.; Smith, C.C.; Poker, D.B. \& Hensley, D.K. (1998). Formation of metallic nanoclusters in silica by ion implantation, Nucl. Inst. Meth. Phys. Res. B 141, 289-293 
Ishikawa, J.; Tsuji, H.; Motono, M.; Gotoh, Y.; Arai, N.; Adachi, K. \& Kotaki, H. (2002). Negative-Ion Implantation into Thin $\mathrm{SiO}_{2}$ Film on $\mathrm{Si}$, and Formation of Silver Nanoparticles in the Film, IEEE 12, 690-693

Joseph, B.; Lenka, H.P.; Kuiri, P.K.; Mahapatra, D.P. \& Kesavamoorthy, R. (2007a). Synthesis of alloy metal nanoclusters on silica glass by sequential ion implantation, Intern. J. Nanoscience 6, 423-430

Joseph, B.; Suchan Sandeep, C.S.; Sekhar, B.R.; Mahapatra, D.P. \& Philip, R. (2007b). Nonlinear optical properties of $\mathrm{MeV}$ and $\mathrm{keV}$ ion beam synthesized $\mathrm{Ag}$ nanoclusters, Nucl. Inst. Meth. Phys. Res. B 265, 631-636

Jiang, C.Z. \& Fan, X.J. (2000). In-situ TEM observation of silver nanocrystals in an Agimplanted $\mathrm{SiO}_{2}$ film, Surf. Coat. Technol. 131, 330-333

Khaibullin, R.I.; Osin, Y.N.; Stepanov, A.L. \& Khaibullin, I.B. (1999). Synthesis of metal/polymer composite films by implantation of Fe and $\mathrm{Ag}$ ions in viscous and solid state silicone substrates, Nucl. Inst. Meth. Phys. Res. B 148, 1023-1028

Kurata, H.; Takami, A. \& Koda, S. (1998). Size reduction of gold particles in aqueous solution by pulsed laser irradiation, Appl. Phys. Lett. 72, 789-791

Link, S.; Burda, C.; Mohamed, M.B.; Nikoobakht, B. \& El-Sayed, M.A. (1999). Laser photothermal melting and fragmentation of gold nanorods: Energy and laser pulsewidth dependence, J. Phys. Chem A 103, 1165-1170

Liu, Z.; Wang, H.; Li, H. \& Wang, X. (1998a). Red shift of plasmon resonance frequency due to the interacting $\mathrm{Ag}$ nanoparticles embedded in single crystal $\mathrm{SiO}_{2}$ by implantation, Appl. Phys. Lett. 72, 1823-1825

Liu, Z.; Li, H.; Feng, X.; Ren, S.; Liu, Z. \& Lu, B. (1998b). Formation effects and optical absorption of Ag nanocrystals embedded in single crystal $\mathrm{SiO} 2$ by implantation, $J$. Appl. Phys. 84, 1913-1917

Liu, Z.; Li, H.; Wang, H.; Shen, D.; Wang, X. \& Alkemade, P.F.A. (2000). Favored structure of Ag nanoparticles embedded in $\mathrm{SiO}_{2}$ by implantation: Single crystal with contracted (111) lattice, J. Mater. Res. 15, 1245-1247

Liu, X.F.; Jiang, C.Z.; Feng, R. \& Fu, Q. (2005). Optical absorption, Raman spectra and TEM study of $\mathrm{Ag}$ nanoparticles formed by ion implantation into $\alpha-\mathrm{SiO}_{2}$, Acta Phys. Sinca $54,4633-4637$

Mafune, F.; Kohno, J.; Takeda, Y. \& Kondow, T. (2002). Growth of gold clusters into nanoparticles in a solution following laser-induced fragmentation, J. Phys. Chem. $B$ $106,8555-8561$

Marques, C.; da Silva, R.C.; Wemans, A.; Maneira, M.J.P.; Kozanecki, A.; \& Alves E. (2006). Optical properties tailoring by high fluence implantation of Ag ions on sapphire, Nucl. Inst. Meth. Phys. Res. B 242, 104-108

Matsunami, N. \& Hosono H. (1993a). Anomalous fringe pattern of Ag colloid in phosphateglasses by implantation, Nucl. Inst. Meth. Phys. Res. B 80, 1233-1236

Matsunami, N. \& Hosono H. (1993b). Colloid formation effects on depth profile of implanted $\mathrm{Ag}$ in $\mathrm{SiO}_{2}$ glass, Appl. Phys. Lett. 63, 2050-2053

Mazzoldi, P.; Tramontin, I.; Boscolo-Boscoletto, A.; Battaglin, G. \& Arnold, G.W. (1993). Substrate effects in silver-implanted glasses, Nucl. Inst. Meth. Phys. Res. B 80-81, 1192-1196

Mazzoldi, P. \& Mattei, G. (2007). Some aspects of ion implantation technique in nanostructured materials, Phys. Stat. Sol. A 204, 621-630 
Magruder III, R.H.; Osborne Jr., \& D.H. Zuhr, R.A. (1994). Non-linear optical properties of nanometer dimension $\mathrm{Ag}-\mathrm{Cu}$ particles in silica formed by sequential ion implantation, J. Non.-Cryst. Solids 176, 299-303

Magruder III, R.H.; Zuhr, R.A. \& Osborne Jr., D.H. (1995). Modification of the optical properties of glass by sequential ion implantation, Nucl. Inst. Meth. Phys. Res. B 99, 590-593

Magruder III, R.H.; Anderson, T.S.; Zuhr, R.A. \& Thomas, D.K. (1996). Formation and optical characterization of multi-component Ag-Sb nanometer dimension colloids formed by sequential ion implantation in silica, Nucl. Inst. Meth. Phys. Res. B 108, 305-312

Magruder III, R.H. \& Meldrum, A. (2007) The effect of Ti and O on the optical properties and microstructure of $\mathrm{Ag}$ nanocrystals formed in silica by sequential ion implantation, J. Non.-Cryst. Solids 353, 4813-4818

Magruder III, R.H.; Robinson, S.J.; Smith, C.; Meldrum, A.; Halabica, A.; \& Haglund Jr., R.H. (2009). Dichroism in Ag nanoparticles composites with bimodal size distribution, J. Appl. Phys. 105, 24303-1 - 24303-1

Nistor, L.C.; von Landuyt, J., Barton, J.B., Hole, D.E.; Skelland, N.D. \& Townsend P.D. (1993) Colloid size distribution in ion implanted glass, J. Non.-Cryst. Solids 162, 217-224

Osborne Jr., D.H.; Haglund Jr., R.F.; Gonella, F. \& Garrido, F. (1998). Laser-induced sign reversal of the nonlinear refractive index of Ag nanoclusters in soda-lime glass, Appl.Phys. B 66, 517-521

Palpant, B (2006). Third-order nonlinear optical response of metal nanoparticles, In: NonLinear Optical Properties of Matter, Papadopoulos, M.G. (Ed.) Springer, Berlin, 461508

Peña, O.; Cheang-Wong, J.C.; Rodríguez-Fernandez, L.; Arenas-Alatorre, J.; Crespo-Sosa, A.; Rodríguez-Iglesias, V. \& Oliver, A. (2007). Metal and metal oxide nanoparticles produced by ion implantation in silica: A microstructural study unsing HRTEM, Nucl. Inst. Meth. Phys. Res. B 257, 99-103

Pham, M.T.; Matz, W. \& Seifarth H. (1997). Surface roughness with nanometer-scale Ag particles generated by ion implantation, Anal. Chim. Acta 350, 209-220

Qian, Y.; Ila, D.; Zimmerman, R.L.; Poker, D.B.; Boatner, L.A. \& Hensley, D.K. (1997). MeV silver ion implantation induced changes in optical properties of $\mathrm{MgO}(100), \mathrm{Nucl}$. Inst. Meth. Phys. Res. B 127, 524-527

Rahmani, M.; Abu-Hassan, L.H.; Townsend, P.D.; Wilson, I.H.; and Destefanis, G.L. (1988). Silver colloid formation in $\mathrm{Ag}^{+}$implanted $\mathrm{LiNbO}_{3}, \mathrm{Nucl}$. Inst. Meth. Phys. Res. B 32, 56-60

Rahmani, M. and Townsend, P.D. (1989). $\mathrm{Ag}^{+}$implantation in $\mathrm{Al}_{2} \mathrm{O}_{3}, \mathrm{LiNbO}_{3}$ and quartz, Vacuum 39, 1157-1162

Kreibig U. \& Vollmer M. (1995). Optical Properties of Metal Clusters, Springer, Berlin

Ren, F.; Jiang, C.Z.; Chen, H.B.; Shi, Y.; Liu, C. \& Wang, J.B. (2004a). Metal alloy and monoelemental nanoclusters in silica formed by sequential ion implantation and annealing in selected atmosphere, Physics B 353, 92-97

Ren, F.; Jiang, C.Z.; Zhang, L.; Shi, Y.; Wang, J.B. \& Wang, R.H. (2004b). Formation and microstructural investigation of $\mathrm{Ag}-\mathrm{Cu}$ alloy nanoclusters embedded in $\mathrm{SiO}_{2}$ formed by sequential ion implantation, Micron 35, 489-493 
Ren, F.; Jiang, C.Z.; Liu, C. \& Shi, Y. (2005a). Alloy and core-shell nanoclusters formed by sequential ion implantation and thermal annealing, J. Kor. Phys. Soc. 46, S43-S47

Ren, F.; Jiang, C.Z.; Fu, D.J. \& Ru, Q. (2005b). Raman scattering studies of Ag nanocluster composites formed by ion implantation into silica, Jap. J. Appl. Phys. 44, 8512-8514

Ren, F.; Jiang, C.Z.; Liu, C.; Fu, D. \& Shi, Y. (2005c). Interface influence on the surface plasmon resonance of Ag nanocluster composite, Solid State Comm. 135, 268-272

Ren, F.; Jiang, C.Z.; Liu, C.; Wang, J. \& Oku, T. (2006). Controlling the morphology of Ag nanoclusters by ion implantation to different doses and subsequent annealing, Phys. Rev. Lett. 97, 165501-1 - 165501- 4

Ren, F.; Jiang, C.Z.; Cai, G.X.; Fu, Q. \& Shi, Y. (2007). Fabrication of hollow nanoclusters by ion implantation, Nucl. Inst. Meth. Phys. Res. B 262, 201-204

Ren, F.; Cai, G.X.; Xiao, X.H.; Fan, L.X.; Liu, C.; Fu, D.J.; Wang, J.B. \& Jiang, C.Z. (2008). Ion irradiation induced hollow and sandwiched nanoparticles, J. Appl. Phys. 103, 843308-1 - 843308-4

Ren, F.; Xiao, X.H.; Cai, G.X.; Wang, J.B. \& Jiang, C.Z. (2009). Engineering embedded metal nanoparticles with ion beam technology, Appl. Phys. A 96, 317-325

Rodríguez -Iglesias, V.; Silva-Pereyra, H.G.; Cheang-Wong, J.C.; Reyes-Esqueda, J.A.; Rodríguez-Fernandez, L.; Crespo-Sosa, A.; Kellerman, G. \& Oliver, A. (2008). MeV $\mathrm{Si}$ ion irradiation effects on the optical absorption properties of metallic nanoparticles embedded in silica. Nucl. Inst. Meth. Phys. Res. B 266, 3138-3142

Roiz, J.; Oliver, A.; Munoz, E.; Rodrıguez-Fernandez, L.; Hernandez, J.M. \& Cheang-Wong, J.C. (2004). Modification of the optical properties of Ag-implanted silica by annealing in two different atmospheres, J. App. Phys. 95, 1783-1791

Romanyuk, A.; Spassov, V. \& Melnik, V. (2006). Influence of in situ ultrasound treatment during ion implantation on formation of silver nanoparticles in silica, J. Appl. Phys. 99, 034314-1 - 034314-4

Sahu, G.; Rath, S.K.; Joseph, B.; Roy, G.S. \& Mahapatra, D.P. (2009). Saturation effects observed in high fluence heavy ion implantation at few tens of keV, Vacuum 83, 836-840

Saito, Y. \& Kitahara, A. (2000). Absorption in the visible region of $\mathrm{LiNbO}_{3}$ sequentially implanted with Ag and Cu, J. Appl. Phys. 87, 1276-1279

Sarkisov, S.S.; Williams, E.K.; Curley, M.J.; Smith, C.C.; Ila, D.; Venkateswarlu, P.; Poker, D.B. \& Hensley, D.K. (1998a). Mechanisms of formation of nonlinear optical guide structures in metal cluster composites produced by ion beam implantation, Mat. Res. Soc. Symp. Proc. 504, 357- 362

Sarkisov, S.S.; Williams, E.K.; Curley, M.J.; Ila, D.; Venkateswarlu, P.; Poker, D.B. \& Hensley, D.K. (1998b). Third order optical nonlinearity of colloidal metal nanoclusters formed by MeV ion implantation, Nucl. Inst. Meth. Phys. Res. B 141, 294-298

Sarkisov, S.S.; Williams, E.K.; Curley, M.J.; Smith, C.C.; Ila, D.; Poker, D.B.; Hensley, D.K.; Banks, C. \& Penn, B. (1998c). Nonlinear optical waveguides based on metal nanocluster composites produced by ion beam implantation, Proc. SPIE. 3283, 942948

Sarkisov, S.S.; Williams, E.K.; Curley, M.J.; Ila, D.; Svetchnikov, V.L.; Pan, V.M.; Poker, D.B.; Hensley, D.K.; Banks, C.; Penn, B. \& Wang, J.W. (1998d). Nonlinear optical waveguides produced by Mev metal ion beam implantation of lithium niobate, Proc. SPIE. 3413, 98-110 
Sarkisov, S.S.; Curley, M.J.; Williams, E.K.; Ila, D.; Svetchnikov, V.L.; Zandbergen, H.W.; Zykov, G.A.; Poker, D.B. \& Hensley, D.K. (1999). Fabrication of nonlinear lightguiding nanocomposute structures by metal ion implantation. Proc. SPIE. 3790, 4355

Sarkisov, S.S.; Curley, M.J.; Williams, E.K.; Ila, D.; Svetchnikov, V.L.; Zandbergen, H.W.; Zykov, G.A.; Banks, C.; Wang, J.-C.; Poker, D.B. \& Hensley, D.K. (2000). Nonlinear optical waveguides produced by $\mathrm{MeV}$ ion implantation in $\mathrm{LiNbO}_{3}$, Nucl. Inst. Meth. Phys. Res. B 166-167, 750-757

Sarychev, A. \& Shalaev V. (2007). Electrodynamics of metamaterials, World Sci. Publ., New York

Shang, D.Y., Saito, Y., Kittaka, R., Taniguchi, S. \& Kitahara, A. (1996). Optical properties of $\mathrm{LiNbO}_{3}$ implanted with Ag ions, J. Appl. Phys. 80, 6651-6654

Sheik-Bahae, M.; Said A.A.; Wei, T.-Z.; Hagan, D.J. \& van Stryland, E.W. (1990). Sensitive measurement of optical nonlinearities using a single beam, IEEE J. Quant. Electr. 29, 760-769

Stepanov, A.L.; Hole, D.E., Bukharaev, A.A.; Townsend, P.D. \& Nurgazizov, N.I. (1998). Reduction of the size of the implanted silver nanoparticles in float glass during excimer laser annealing, Appl. Surf. Sci. 136, 298-305

Stepanov, A.L.; Hole, D.E. \& Townsend, P.D. (1999a). Reflectance of the dielectrics layers containing metal nanoparticles formed by ion implantation, J. Non.-Cryst. Solids 224, 275-279

Stepanov, A.L.; Hole, D.E. \& Townsend, P.D. (1999b). Formation of silver nanoparticles in soda-lime silicate glass by ion implantation near room temperature, J. Non.-Cryst. Solids 260, 67-74

Stepanov, A.L.; Hole, D.E. \& Townsend, P.D. (1999c). Modification of size distribution of ion implanted silver nanoparticles in sodium silicate glass using laser and thermal annelaing, Nucl. Instrum. Meth. Phys. Res. 149, 89-98

Stepanov, A.L.; Hole, D.E. \& Townsend, P.D. (2000a). Optical reflectance of insulators containing implanted metal nanoparticles, Nucl. Instrum. Meth. Phys. Res. 161-163, 913-916

Stepanov, A.L.; Hole, D.E. \& Townsend, P.D. (2000b). Excimer laser annealing of glasses containing implanted metal nanoparticles, Nucl. Instrum. Meth. Phys. Res. 166-167, 26-30

Stepanov, A.L.; Abdullin, S.N.; Khaibullin, R.I., Valeev, V.F.; Osin, Yu.N.; Bazarov, V.V. \& Khaibullin, I.B. (1995). Ion synthesis of colloidal silver nanoclusters in the organic substrate, Mat. Res. Soc. Proc. 392, 267-272

Stepanov, A.L. (2000c). Optical reflection from dielectric layers containing metal particles formed by ion implantation, Optics and Spectroscopy 89, 408-412

Stepanov, A.L.; Zhikharev, V.A.; Hole, D.E., Townsend, P.D.; Khaibullin, I.B. (2000d). Depth distribution of $\mathrm{Cu}, \mathrm{Ag}$ and $\mathrm{Au}$ implanted at low energy into insulators, Nucl. Instrum. Meth. Phys. Res. 166-167, 882-886

Stepanov, A.L.; Popok, V.N.; Hole, D.E. \& Bukharaev, A.A. (2001a). Interaction of highpower laser pulses with glasses containing implanted metallic nanoparticles, Physics of the Solid State 43, 2192-2198

Stepanov, A.L. \& Popok, V.N. (2001b). Laser and thermal modification of silver-ion implanted glasses, J. Appl. Spectr. 68, 164-169 
Stepanov, A.L.; Hole, D.E. \& Popok, V.N. (2001c). Effect of the target surface temperature on the distribution of nanoparticles formed by ion implantation, Tech. Phys. Lett. 27, 554-556

Stepanov, A.L.; Hole, D.E. \& Bukharaev, A.A. (2002a). Interaction of high-power excimerlaser pulses with soda-lime silicate glass containing ion-implanted metal nanoparticles, Vacuum 64, 169-177

Stepanov, A.L.; Popok, V.N. and Hole, D.E. (2002d). Formation of metallic nanoparticles in silicate glass througth ion implantation, Glass Phys. Chem. 28, 90-95

Stepanov, A.L. and Hole, D.E. (2003c). Laser annealing of metal-dielectric nanocomposites formed by ion implantation, Phil. Mag. Lett. 82, 149-155

Stepanov, A.L. (2002b). Formation of metal nanoparticles in dielectrics by low energy ion implantation, In: Recent Res. Devel. Appl. Phys. 5, 1-25, Transworld Res. Network, Kerala

Stepanov, A.L. \& Popok, V.N. (2003a). Effect of the ion beam current density on the formation of implanted metal nanoparticles in a dielectric matrix, Tech. Phys. Lett. 29, 977-979

Stepanov, A.L. (2003b). Modification of implanted metal nanoparticles in the dielectrics by high-power laser pulses, Rev. Adv. Mater. Sci. 4, 45-60

Stepanov, A.L. (2002c). Laser annealing of glasses with implanted metal nanoparticles, In: Recent Res. Devel. Non.-Cryst. Solids 3, 177-198, Transworld Res. Network, Kerala

Stepanov, A.L. \& Popok, V.N. (2004a). Nanosecond pulse laser and furnace annealing of silver nanoparticles formed by implantation is silicate glass, Surf. Coat. Thechnol. 185, 30-37

Stepanov, A.L. \& Popok, V.N. (2004b). Nanostructuring of silicate glass under low-energy Ag-ion implantation, Surf. Sci. 566-568, 1250-1254

Stepanov, A.L. (2005a). Optical extinction of metal nanoparticles synthesised in polymers by ion implantation, In: Metal-Polymer Nanocomposites, edited by L. Nicolais, G. Carotenuto (Eds.), 241-263, John Wiley \& Sons Publ, London

Stepanov, A.L. \& Popok, V.N. (2005b). Synthesis of silver nanoparticles by the ion implantation method and investigation of their optical properties, J. Appl. Spectr. 72, 229-234

Stepanov, A.L.; Chichkov, B.N.; Valeev, V.F.; Nuzhdin, V.I. \& Faizrakhmanov, I.A. (2008a). Modification of ion-synthesized silver nanoparticles in glass by high-power eximer laser pulses, Tech. Phys. Lett. 34, 184-186

Stepanov, A.L.; Valeev, V.F.; Nuzhdin, V.I.; Faizrakhmanov, I.A. \& Chichkov, B.N. (2008b). laser annealing induced melting of silver nanoparticles in a glass matrix, Tech. Phys. Lett. 34, 1014-1017

Stepanov, A.L.; Valeev, V.F.; Nuzhdin, V.I.; Bazarov, V.V.; \& Faizrakhmanov, I.A. (2009). Excimer laser-assisted annealing of silicate glass with ion-synthesised silver nanoparticles, Tech. Phys. 54, 1504-1510

Steiner, G.; Pham, M.T.; Kuhne, Ch. \& Salzer, R. (1998) Surface plasmon resonance within ion implanted silver clusters, Fresenius J. Anal Chem. 362, 9-14

Takeda, Y.; Plaksin, O.A.; Lu, J. \& Kishimoto N. (2006). Optical nonlinearity of metal composites fabricated by negative ion implantation, Vacuum 80, 776-779

Townsend, P.T.; Chandler, P.J. \& Zhang L. (1994). Optical Effects of Ion Implantation, Cambridge Univ. Press, Cambridge 
Townsend, P.T. \& Olivares, J. (1997) Laser processing of insulator surface, Appl. Surf. Sci. 109-110, 275-282

Treilleux, M.; Thevenard, P.; Ghassagne, G. \& Hobbs L.H. (1978). Observation of implanted potassium aggregates in $\mathrm{MgO}$ single crystal, Phys. Stat. Sol. A 48, 425-430

Tsuji, H.; Kurita, K.; Gotoh, Y.; Kishimoto, N. \& Ishikawa, J. (2002a). Optical absorption properties of $\mathrm{Cu}$ and $\mathrm{Ag}$ double negative-ion implanted silica glass, Nucl. Inst. Meth. Phys. Res. B 195, 315-319

Tsuji, H.; Kurita, K. \& Motono, M. (2002b).Control of optical absorption band due to Cu/Ag nanoparticles in $\mathrm{SiO}_{2}$ glass by dual ion implantation of $\mathrm{Cu}^{-}$and $\mathrm{Ag}$, J. Vac. Soc. Jap. $45,528-532$

Tsuji, H.; Sugahara, H.; Gotoh, Y. \& Ishikawa, J. (2002c). Surface modification of $\mathrm{TiO}_{2}$ (rutile) by metal negative ion implantation for improving catalytic properties. Surf. Coat. Thechnol. 158-159, 208-213

Tsuji, H.; Arai, N.; Motono, M.; Gotoh, Y.; Abachi, K.; Kotaki, H. \& Ishikawa, J. (2003a). Study on optical reflection property from multilayer on Si substrate including nanoparticles in $\mathrm{SiO}_{2}$ layer, Nucl. Inst. Meth. Phys. Res. B 206, 615-619

Tsuji, H.; Sugahara, H.; Gotoh, Y. \& Ishikawa, J. (2003b). Improvement of photocatalytic efficiency of rutile titania, Nucl. Inst. Meth. Phys. Res. B 206, 249-253

Tsuji, H.; Arai, N.; Matsumoto, T.; Ueno, K.; Gotoh, Y.; Abachi, K.; Kotaki, H. \& Ishikawa J. (2004). Silver nanoparticle formation in thin oxide layer on silicon by silvernegative-ion implantation for Coulomb blockade at room temperature, Appl. Surf. Sci. 238, 132-137

Tsuji, H.; Arai, N.; Matsumoto, T.; Ueno, K.; Abachi, K.; Kotaki, H.; Gotoh, Y. \& Ishikawa, J. (2005a).Delta layer formation of silver nanoparticles in thin silicon dioxide film by negative ion implantation, Surf. Coat. Technol. 196: 39-43

Tsuji, H.; Arai, N.; Matsumoto, T.; Ueno, K.; Abachi, K.; Kotaki, H.; Gotoh, Y. \& Ishikawa, J. (2005b). Delta layer formation of silver nanoparticles in thin silicon dioxide film by negative ion implantation, Surf. Coat. Technol. 196: 39-43

Tsuji, H.; Sakai, N.; Sugahara, H.; Gotoh, Y. \& Ishikawa, J. (2005c). Silver negative-ion implantation to sol-gel $\mathrm{TiO}_{2}$ film for improving photocatalytic property under fluorescent light, Nucl. Inst. Meth. Phys. Res. B 237, 433-437

Tsuji, H.; Sakai, N.; Gotoh, Y. \& Ishikawa, J. (2006). Photocatalytic properties of sol-gel titania film under fluorescent-ligth irradiation improved by silver negative-ion implantation, Nucl. Inst. Meth. Phys. Res. B 242, 129-132

Wang Y.H.; Jiang C.Z.; Ren, F.; Wang, Q.Q.; Chen, D.J. \& Fu, D.J. (2007). Effect of ingredient on optical properties of $\mathrm{Ag} / \mathrm{Cu}$ metal alloy nanoclusters in silica glass, J. Mater. Sci. 42, 7294-7298

Wang, Y.H.; Jiang, C.Z.; Xiao, X.H. \& Chen, D.J. (2008). Third-order nonlinear optical response of $\mathrm{Cu} / \mathrm{Ag}$ nanoclusters by ion implantation under $1064 \mathrm{~nm}$ laser exitation, Physica B 403, 2143-2147

Wang, Y.H.; Peng, S.J.; Lu, J.D.; Wang, R.W.; Mao, Y.I. \& Chen, Y.G. (2009a). Optical properties of $\mathrm{Cu}$ and $\mathrm{Ag}$ nanoparticles synthesized in glass by ion implantation, Vacuum 83, 408-411

Wang, Y.H.; Peng, S.J.; Lu, J.D.; Wang, R.W.; Chen, Y.G. \& Mao Y.I. (2009b). Nonlinear optical properties of Ag nanocluster composite fabricated by $200 \mathrm{keV}$ negative ion implantation, Vacuum 83, 412-415 
White, C.W.; Thomas, D.K.; Hensley, D.K.; McCallum, J.C., Pogany, A.; Haglund Jr., R.F.; Magruder, R.H.; \& Yang, L. (1993). Colloidal Au and Ag precipitation formed in $\mathrm{Al}_{2} \mathrm{O}_{3}$ by ion implantation and annealing, Nanostruc. Mat. 3, 447-457

Williams, E.K.; Ila, D.; Sarkisov, S.S.; Curley, M.J.; Poker, D.B.; Hensley, D.K. \& Borel C. (1998a). Study of the effects of $\mathrm{VeV} \mathrm{Ag}, \mathrm{Cu}, \mathrm{Au}$ and $\mathrm{Sn}$ implantation on the optical properties of $\mathrm{LiNbO}_{3}$, Mat. Res. Soc. Symp. Proc. 504, 363-369

Williams, E.K.; Ila, D.; Sarkisov, S.S.; Curley, M.J.; Cochrane, J.C.; Poker, D.B.; Hensley, D.K. \& Borel, C. (1998b). Study of the effects of MeV Ag and Au implantation on the optical properties of $\mathrm{LiNbO}_{3}$, Nucl. Inst. Meth. Phys. Res. B 141, 268-273

Williams, E.K.; Ila, D.; Darwish, A.; Poker, D.B.; Sarkisov, S.S.; Curley, M.J.; Wang, J.-C.; Svetchnikov, V.L. \& Zandbergen H.W. (1999). Characterisation of silver coloids formed in $\mathrm{LiNbO}_{3}$ by $\mathrm{Ag}$ and $\mathrm{O}$ implantation at room and elevated temperatures, Nucl. Inst. Meth. Phys. Res. B 148, 1074-1078

Wood, R.A.; Townsend, P.D.; Skelland, N.D.; Hole, D.E.; Barton, J. \& Afonso, C.N. (1993). Annealing of ion implanted silver colloids in glass, J. Appl. Phys. 74, 5754-5756

Xiao, X.H.; Jiang, C.Z.; Ren, F.; Wang, J. \& Shi, Y. (2006). Ion implantation inducing nanovoids characterization by TEM and STEM, Solid State Comm. 137, 362-365

Xiao, X.H.; Ren, F.; Wang, J.B.; Liu, C. \& Jiang, C.Z. (2007a). Formation of aligned silver nanoparticles by ion implantation, Mater. Lett. 61, 4435-4437

Xiao, X.H.; Guo, L.P.; Ren, F.; Wang, J.B.; Fu, D.J.; Chen, D.L.; Wu, Z.Y.; Jia, Q.J.; Liu, C. \& Jang, C.Z. (2007b). Formation of metal nanopartilcles in silica by the sequential implantation of Ag and Cu, Appl. Phys. A 89, 681-684

Xiao, X.H.; Xu, J.X.; Ren, F.; Liu, C. \& Jiang, C.Z. (2008). Fabrication of Ag nanoclusters in single-crystal MgO by high-energy ion implantation, Physica E 40, 705-708

Zhang, L.; Jiang, C.Z.; Ren, F.; Chen, H.-B.; Shi, Y. \& Fu, Q. (2004). Optical absorption of nanoclusters by sequentially implanting into $\mathrm{SiO}_{2}$ glass and subsequently annealing in a selected atmosphere, Acta Phys. Sinica 53, 2910-2914

Zimmerman, R.L., Muntele, C.I. \& Ila, D. (2005). MeV ion beam induced change in the linear optical properties of MgO, Surf. Coat. Technol. 196, 85-88

Zuhr, R.A.; Magruder III, R.H. \& Anderson, T.S. (1998). Formation and optical properties of intermetallic nanoclusters formed by sequential ion implantation, Surf. Coat. Technol. 101, 401-408 


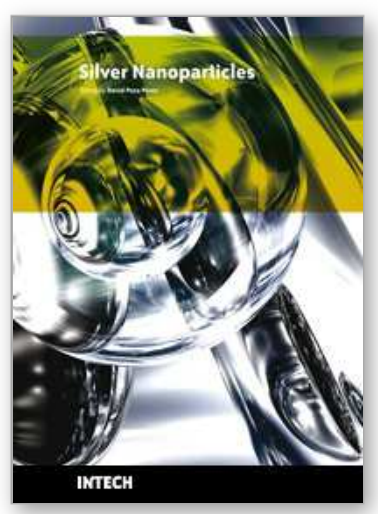

\author{
Silver Nanoparticles \\ Edited by David Pozo Perez
}

ISBN 978-953-307-028-5

Hard cover, 334 pages

Publisher InTech

Published online 01, March, 2010

Published in print edition March, 2010

Nanotechnology will be soon required in most engineering and science curricula. It cannot be questioned that cutting-edge applications based on nanoscience are having a considerable impact in nearly all fields of research, from basic to more problem-solving scientific enterprises. In this sense, books like "Silver Nanoparticles" aim at filling the gaps for comprehensive information to help both newcomers and experts, in a particular fast-growing area of research. Besides, one of the key features of this book is that it could serve both academia and industry. "Silver nanoparticles" is a collection of eighteen chapters written by experts in their respective fields. These reviews are representative of the current research areas within silver nanoparticle nanoscience and nanotechnology.

\title{
How to reference
}

In order to correctly reference this scholarly work, feel free to copy and paste the following:

Andrey L. Stepanov (2010). Linear and Nonlinear Optical Properties of Silver Nanoparticles Synthesized in Dielectrics by Ion Implantation and Laser Annealing, Silver Nanoparticles, David Pozo Perez (Ed.), ISBN: 978953-307-028-5, InTech, Available from: http://www.intechopen.com/books/silver-nanoparticles/linear-andnonlinear-optical-properties-of-silver-nanoparticles-synthesized-in-dielectrics-by-ion-im

\section{INTECH}

open science | open minds

\section{InTech Europe}

University Campus STeP Ri Slavka Krautzeka 83/A 51000 Rijeka, Croatia Phone: +385 (51) 770447 Fax: +385 (51) 686166 www.intechopen.com

\section{InTech China}

Unit 405, Office Block, Hotel Equatorial Shanghai No.65, Yan An Road (West), Shanghai, 200040, China 中国上海市延安西路65号上海国际贵都大饭店办公楼405单元 Phone: +86-21-62489820

Fax: $+86-21-62489821$ 
(C) 2010 The Author(s). Licensee IntechOpen. This chapter is distributed under the terms of the Creative Commons Attribution-NonCommercialShareAlike-3.0 License, which permits use, distribution and reproduction for non-commercial purposes, provided the original is properly cited and derivative works building on this content are distributed under the same license. 